Supporting Information for:

\title{
Polymerization-Induced Hierarchical Self-Assembly: From Monomer to Complex Colloidal Molecules and Beyond
}

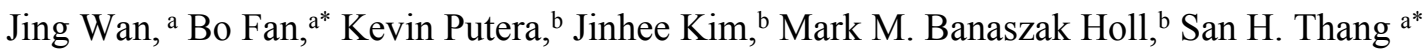

${ }^{a}$ School of Chemistry, ${ }^{b}$ Department of Chemical Engineering, Monash University, Clayton, VIC 3800,

Australia 


\section{Additional Experimental Details}

\section{Materials}

Diisopropyl carbodiimide (DIC; $>99 \%$ ) was purchased from Oakwood Chemical (USA). 4Dimethylaminopyridine (DMAP; 99\%) was purchased from Alfa Aesar. 4-Cyano-4 (((dodecylthio) carbonothioyl) thio) pentanoic acid (CDTPA; 97\%) was purchased from Boron Molecular (Australia). Randomly methylated- $\beta$-cyclodextrin $\left(\mathrm{M} \beta \mathrm{CD}, M_{\mathrm{n}} \sim 1300 \mathrm{~g} / \mathrm{mol}\right.$, average degree of substitution $=11.8$, 98\%, Zhiyuan Biotech, China) was used as received. Poly(ethylene glycol) methyl ether ( $\mathrm{mPEG}_{113}$, average $M_{\mathrm{n}} 5,000 \mathrm{~g} / \mathrm{mol} ; \mathrm{mPEG}_{45}$, average $M_{\mathrm{n}} 2,000 \mathrm{~g} / \mathrm{mol}$ ), tert-butyl methacrylate (tBMA), tert-butyl acrylate (tBA) and styrene (st) were purchased from Sigma Aldrich (Australia). 4,4'-Azobis(4cyanopentanoic acid) (ACVA) was purchased from Wako Pure Chemical Industries, Ltd. Deionized (DI) water was obtained from Milli-Q system (Millipore). All the other solvents were obtained from commercial sources and were used as received unless noted otherwise.

\section{Characterization methods}

Dynamic light scattering (DLS) measurements were performed at $25{ }^{\circ} \mathrm{C}$ using Malvern Zetasizer Nano ZS. The aqueous dispersions containing the diblock copolymer nano-objects were diluted to 0.10 $\% \mathrm{w} / \mathrm{v}$ by DI water. Light scattering was detected at $90^{\circ}$ and hydrodynamic diameters were determined by assuming spherical, non-interacting, perfectly monodisperse particles.

${ }^{1} \mathrm{H}$ Nuclear magnetic resonance (NMR) spectra were recorded on a Bruker Avance 400 NMR spectrometer at frequencies of $400 \mathrm{MHz}$. NMR chemical shifts $(\delta)$ are reported in ppm and were calibrated against residual solvent signals of $\mathrm{CDCl}_{3}(\delta 7.26)$ and $\mathrm{D}_{2} \mathrm{O}(\delta 4.79)$. Samples were dissolved in $\mathrm{CDCl}_{3}$ or $\mathrm{D}_{2} \mathrm{O}$ at $5-10 \mathrm{mg} \mathrm{mL}^{-1}$. The data are reported as chemical shift $(\delta)$.

Gel permeation chromatography (GPC) was performed on a system comprising a Shimadzu LC20AT pump, Shimadzu RID-20A refractive index detector, and SPD-20A UV-visible detector. The GPC is equipped with a guard column (WAT054415) and $3 \times$ Waters GPC columns (WAT044238, WAT044226, WAT044235, $300 \mathrm{~mm} \times 7.8 \mathrm{~mm}$ ). The eluent is DMF with $10 \mathrm{mM} \mathrm{LiBr}$ and eluted at 1 $\mathrm{mL} / \mathrm{min}$ for $45 \mathrm{~min}$ in total, the column was maintained at $40{ }^{\circ} \mathrm{C}$ during elution. The samples were dissolved in DMF with $10 \mathrm{mM} \mathrm{LiBr}$, filtered through $0.20 \mu \mathrm{m}$ syringe filters. A calibration curve was obtained from poly(methyl methacrylate) (PMMA) standards (Agilent) ranging from 960 to $1,568,000$ $\mathrm{g} \mathrm{mol}^{-1}$.

Turbidity was performed using Thermo Scientific Orion AQ4500 turbidimeter.

\section{Preparation of $\mathrm{PEG}_{113}$-CDTPA and $\mathrm{PEG}_{45}$-CDTPA macro-CTA agents}

The synthesis of PEG $_{113}$-RAFT ( PEG $_{113}$-CDTPA) was performed using the same procedure described elsewhere': $\mathrm{mPEG}_{113}(6.0 \mathrm{~g}, 1.2 \mathrm{mmol})$ was dissolved in $30 \mathrm{~mL}$ toluene in a round bottom flask to 
remove water azeotropically by rotary evaporation (repeated 3 times). Dichloromethane $(30 \mathrm{~mL})$ was then added to the flask containing $\mathrm{mPEG}_{113}(6.0 \mathrm{~g}, 1.2 \mathrm{mmol})$. CDTPA (970.0 $\left.\mathrm{mg}, 2.4 \mathrm{mmol}\right)$, DIC (0.3 $\mathrm{g}, 2.4 \mathrm{mmol})$ and DMAP $(29.0 \mathrm{mg}, 0.24 \mathrm{mmol})$ were added to the reaction mixture in sequence. The flask was sealed with a rubber septum. The esterification reaction was allowed to proceed with stirring at room temperature for 24 hours. The solution was cooled at $4{ }^{\circ} \mathrm{C}$ for 1 hour and filtered to remove white precipitate. The polymer was collected by precipitation of the filtered solution in cold diethyl ether 3 times. The resulting pale-yellow polymer $\left(\mathrm{PEG}_{113}\right.$-RAFT) was analyzed by ${ }^{1} \mathrm{H}$ NMR spectroscopy (Figure S1) and GPC (Figure S2). ${ }^{1} \mathrm{H}$ NMR (400 MHz, $\mathrm{CDCl}_{3}$ ): $\delta 4.25(\mathrm{t}, 2 \mathrm{H}), 3.45-3.81$ (m, 452H), $3.37(\mathrm{~s}, 3 \mathrm{H}), 3.31(\mathrm{t}, 2 \mathrm{H}), 2.37-2.65(\mathrm{~m}, 4 \mathrm{H}), 1.86(\mathrm{~s}, 3 \mathrm{H}), 1.68(\mathrm{~m}, 2 \mathrm{H}), 1.25-1.38(\mathrm{~b}, 18 \mathrm{H})$, 0.87 (t, 3H). ${ }^{13} \mathrm{C}$ NMR $\left(150 \mathrm{MHz}, \mathrm{CDCl}_{3}\right): \delta 216.8,171.3,118.9,71.8,70.4,68.8,64.0,58.9,46.2$, $33.7,31.8,29.2,24.7,22.6,14.0$.

For the synthesis of $\mathrm{PEG}_{45}$-CDTPA, same synthesis procedure was used only by replacing $\mathrm{mPEG}_{113}$ with $\mathrm{mPEG}_{45}$. The polymer was purified by dialysis against acetone: methanol co-solvent $(1: 1 \mathrm{v} / \mathrm{v})$ using $1 \mathrm{kDa}$ MWCO membrane. ${ }^{1} \mathrm{H}$ NMR $\left(400 \mathrm{MHz}, \mathrm{CDCl}_{3}\right)$ : $\delta 4.25(\mathrm{t}, 2 \mathrm{H}), 3.45-3.81(\mathrm{~m}, 180 \mathrm{H})$, $3.37(\mathrm{~s}, 3 \mathrm{H}), 3.32(\mathrm{t}, 2 \mathrm{H}), 2.37-2.65(\mathrm{~m}, 4 \mathrm{H}), 1.87(\mathrm{~s}, 3 \mathrm{H}), 1.69(\mathrm{~m}, 2 \mathrm{H}), 1.25-1.39(\mathrm{~b}, 18 \mathrm{H}), 0.88(\mathrm{t}$, $3 \mathrm{H})$.

\section{Synthesis of PEG-b-PS-b-PtBA from PEG-b-PS seeds via emulsion polymerization}

The preparation of $\mathrm{PEG}_{113}-b-\mathrm{PS}_{100}-b-\mathrm{PtBA}$ (targeting $\mathrm{DP}=200$ ): $2 \mathrm{~mL}$ of $\mathrm{PEG}_{113}-b-\mathrm{PS}_{100}$ suspension (3 wt \%) was dialyzed against DI $\mathrm{H}_{2} \mathrm{O}$ using $3.5 \mathrm{kDa}$ MWCO membrane for two days to remove $\mathrm{M} \beta \mathrm{CD}$, $5 \mathrm{~mL}(1.2 \mathrm{wt} \%)$ suspension was obtained after dialysis. ${ }^{1} \mathrm{H}$ NMR results confirmed almost all MBCD was removed. Then, $1908.3 \mathrm{mg}$ of dialyzed $\mathrm{PEG}_{113}-b-\mathrm{PS}_{100}$ suspension (1.2 wt \%, containing $22.9 \mathrm{mg}$, $1.45 \times 10^{-3} \mathrm{mmol}$ of $\left.\mathrm{PEG}_{113}-b-\mathrm{PS}_{100}\right)$, tBA $(37.1 \mathrm{mg}, 0.29 \mathrm{mmol})$ were mixed with $54.6 \mu \mathrm{L} \mathrm{DI} \mathrm{H} \mathrm{H}_{2} \mathrm{O}$ to make a $3 \mathrm{wt} \%$ solid content suspension. The mixture was then sonicated for $10 \mathrm{~min}$ and stirred for 30 min to obtain a cloudy homogeneous suspension that no tBA droplets were visible, and ACVA ( $25 \mu \mathrm{L}$ of $6 \mathrm{mg} \mathrm{ACVA} / \mathrm{mL}$ methanol solution, ACVA/CTA=0.3) was added. The suspension was deoxygenated by 3 cycles of freeze-vacuum-thaw, and immersed into a $70^{\circ} \mathrm{C}$ oil bath for $16 \mathrm{~h}$. The suspension was then cooled to room temperature and exposed to air. 


\section{Calculation of Surface and Interfacial Tension}

Contact angles of liquids on solids are often described with the Young's equation:

$\gamma_{S V}=\gamma_{S L}+\gamma_{L V} \cos \theta$, equation (1)

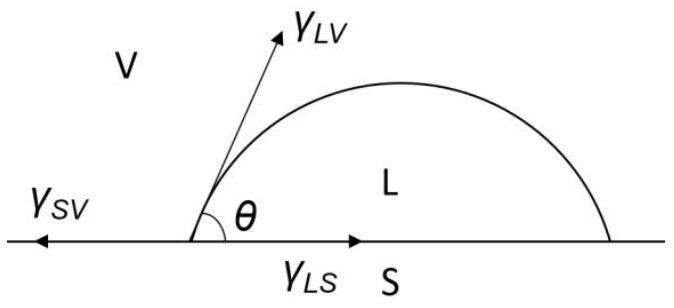

Where $\gamma_{S V}, \gamma_{S L}, \gamma_{L V}$ are the solid/vapor, solid/liquid and liquid/vapor interface tensions. $\theta$ : the contact angle. The surface tension can also be calculated from the Girifalco and Good equation ${ }^{2}$ :

$\gamma_{S L}=\gamma_{S V}+\gamma_{L V}-2 \cdot \phi \cdot\left(\gamma_{S V} \gamma_{L V}\right)^{1 / 2}$, equation (2)

In many cases, $\phi$ is of the order of unity, which is the case for aliphatic compounds where only dispersion forces are present:

$\gamma_{S L} \approx \gamma_{S V}+\gamma_{L V}-2\left(\gamma_{S V} \gamma_{L V}\right)^{1 / 2}$, equation (3)

Combining equation (3) with equation (1), gives:

$$
\gamma_{S V}=\gamma_{L V}(1+\cos \theta)^{2} / 4 \phi^{2} \approx \gamma_{L V}(1+\cos \theta)^{2} / 4
$$

In this study, $\gamma_{L V}$ is water/air surface tension, which is $72.8 \mathrm{mN} \cdot \mathrm{m}^{-1}$ at $20^{\circ} \mathrm{C}$.

Table S1. Summary of surface and interfacial tension of polymers

\begin{tabular}{|c|c|c|c|}
\hline & PS & PtBA & PtBMA \\
\hline $\begin{array}{c}M_{\mathrm{n}, \mathrm{GPC}} \\
\left(\mathrm{kg} \cdot \mathrm{mol}^{-1}\right)\end{array}$ & 57.5 & 21.3 & 17.4 \\
\hline & & & \\
\hline $\begin{array}{c}\text { Contact angle } \\
\theta\left({ }^{\circ}\right)\end{array}$ & $83.0 \pm 0.2$ & $79.8 \pm 0.4$ & $81.2 \pm 0.6$ \\
\hline $\begin{array}{c}\gamma_{S V} \\
\left(\mathrm{mN} \cdot \mathrm{m}^{-1}\right)\end{array}$ & $22.9 \pm 0.1$ & $25.2 \pm 0.3$ & $24.2 \pm 0.5$ \\
\hline $\begin{array}{c}\gamma_{S L} \\
\left(\mathrm{mN} \cdot \mathrm{m}^{-1}\right)\end{array}$ & $14.0 \pm 0.1$ & $12.3 \pm 0.2$ & $13.1 \pm 0.3$ \\
\hline
\end{tabular}




\section{Supplementary Figures}

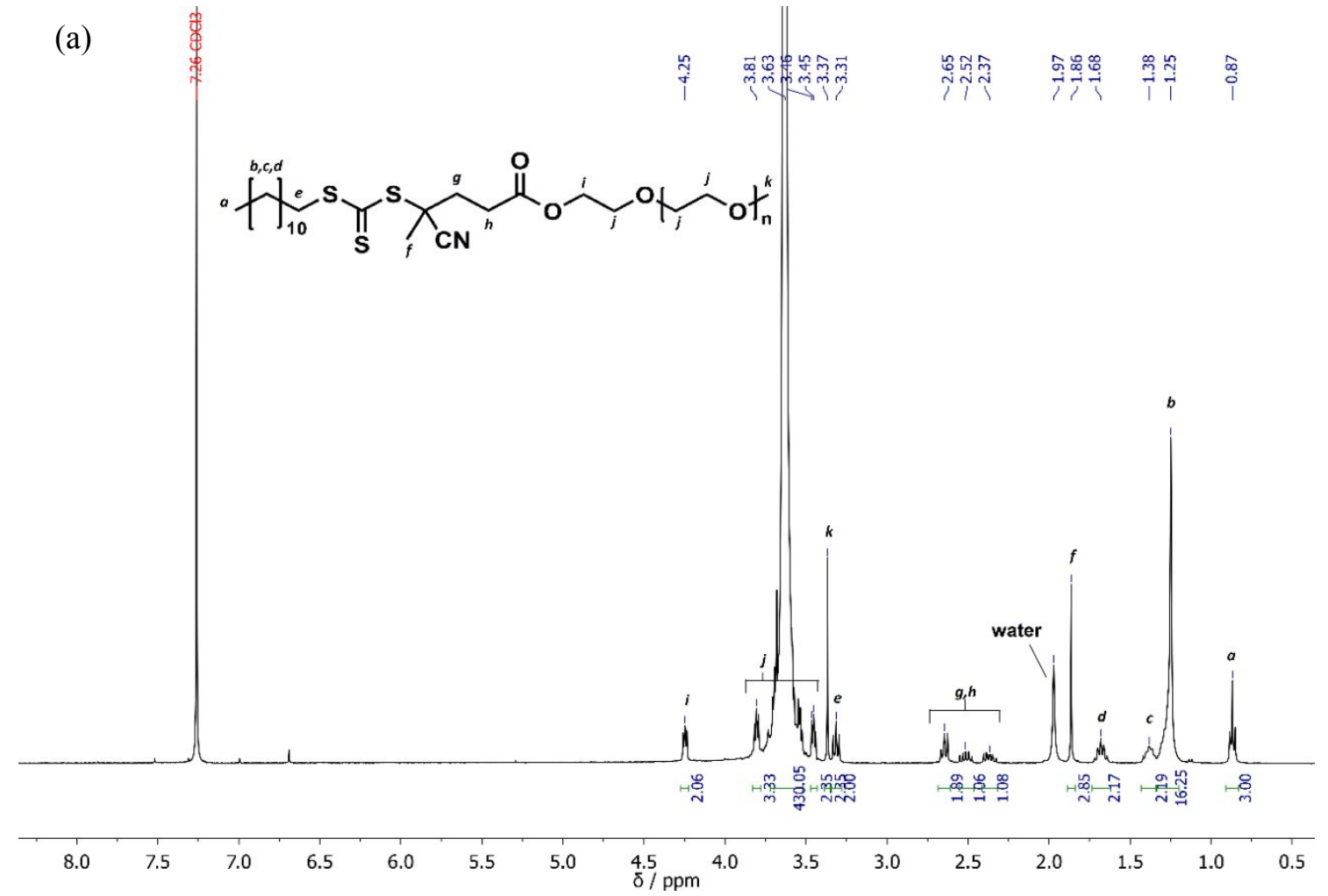

(b)

\section{CHLOROFORM-d}

88

솟

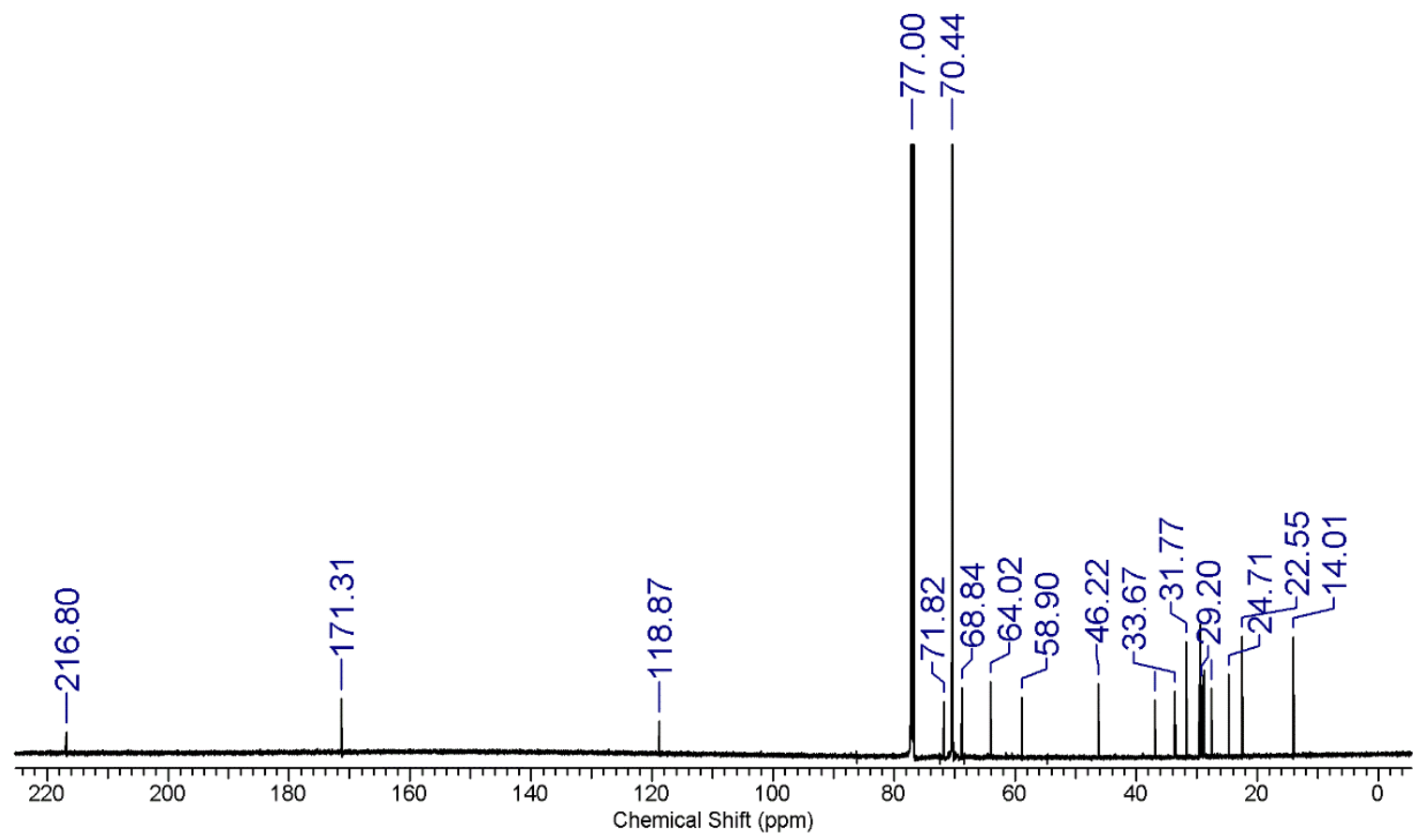


(c)

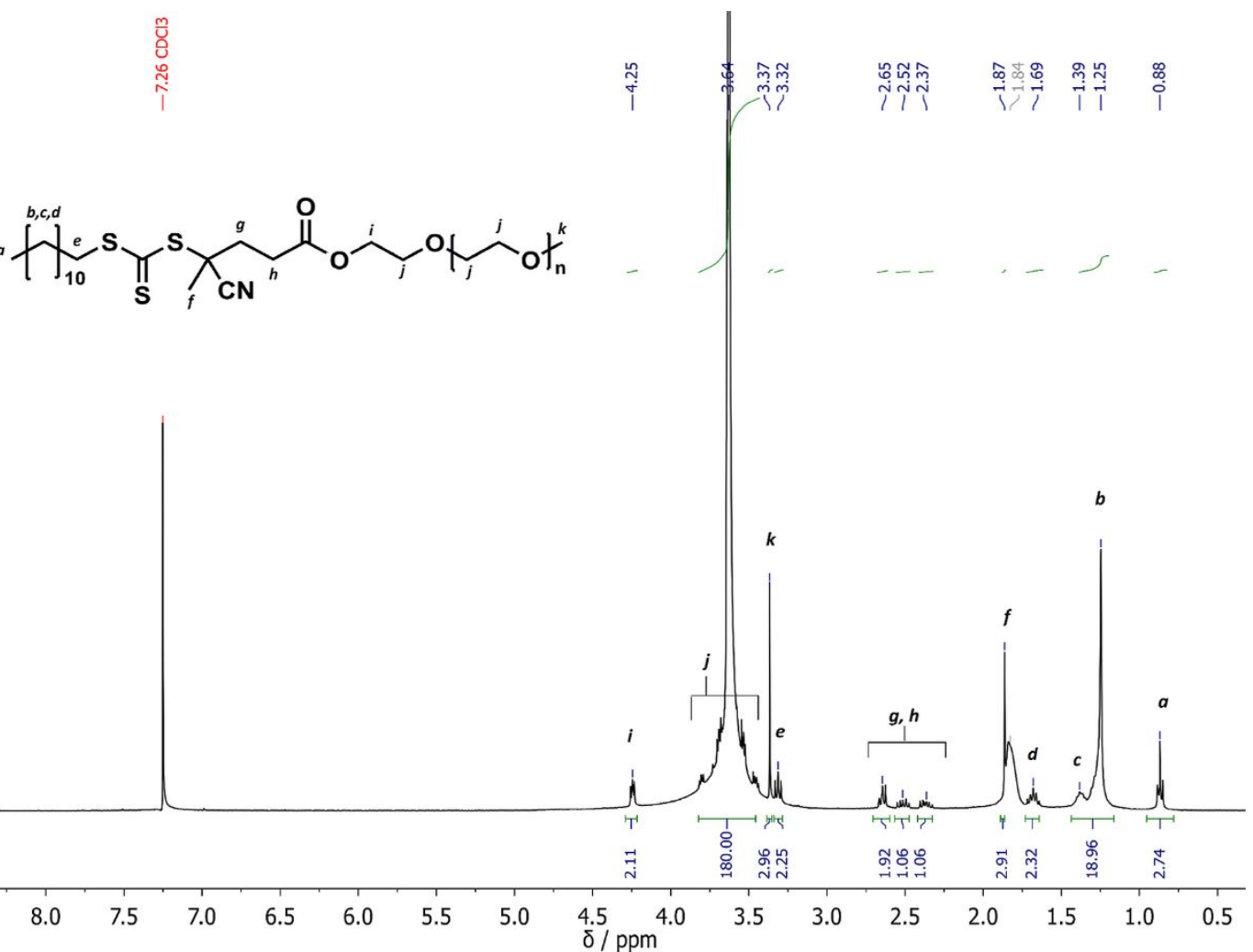

Figure S1. (a) ${ }^{1} \mathrm{H}$ NMR spectrum $\left(400 \mathrm{MHz}, \mathrm{CDCl}_{3}\right)$ and (b) ${ }^{13} \mathrm{C} \mathrm{NMR}$ spectrum $\left(150 \mathrm{MHz}, \mathrm{CDCl}_{3}\right)$ of $\mathrm{PEG}_{113}$-CDTPA. (c) ${ }^{1} \mathrm{H}$ NMR spectrum $\left(400 \mathrm{MHz}, \mathrm{CDCl}_{3}\right.$ ) of $\mathrm{PEG}_{45}$-CDTPA.

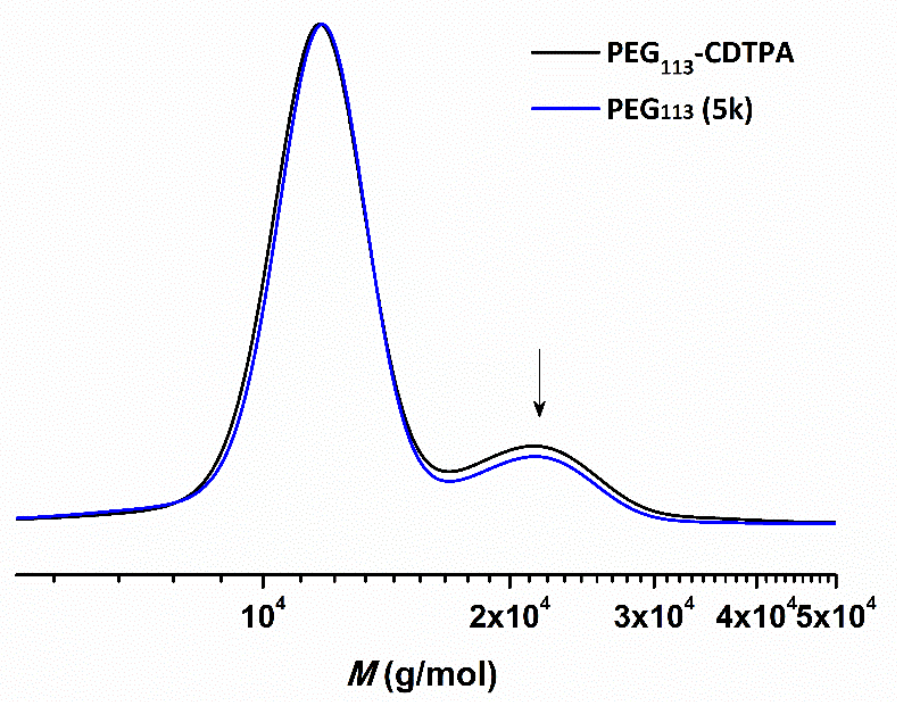

Figure S2. GPC traces of poly(ethylene glycol) methyl ether $\left(\mathrm{PEG}_{113}\right.$, average $\left.M_{\mathrm{n}} 5,000 \mathrm{~g} / \mathrm{mol}\right)$ and synthesized PEG $_{113}$-CDTPA (DMF GPC, PMMA standards). 


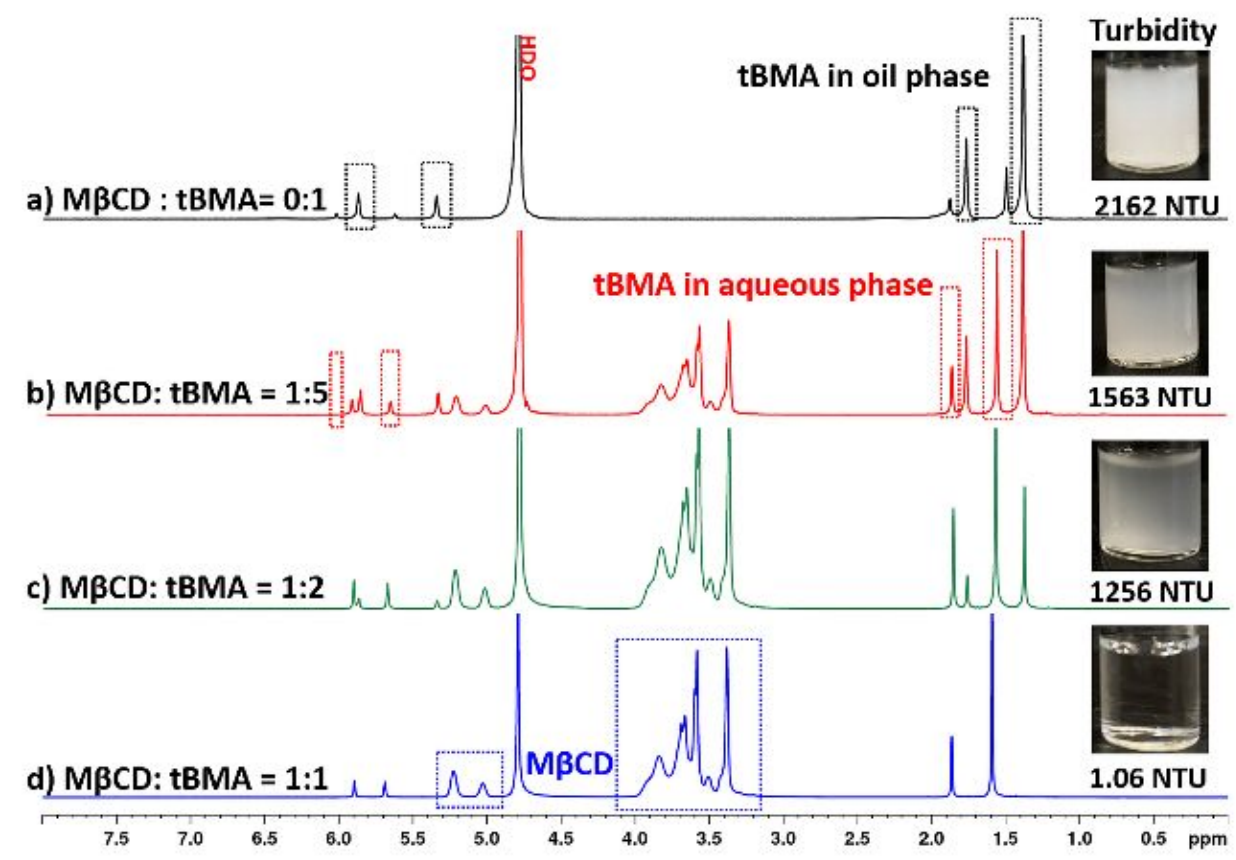

Figure S3. ${ }^{1} \mathrm{H}$ NMR spectra $\left(400 \mathrm{MHz}, \mathrm{D}_{2} \mathrm{O}\right)$ and digital photo of $\mathrm{M} \beta \mathrm{CD} / \mathrm{tBMA}$ in $\mathrm{D}_{2} \mathrm{O}$ with $\mathrm{M} \beta \mathrm{CD}$ : tBMA molar ratio of (a) 0:1, (b) 1:5, (c) 1:2 and (d) 1:1, the concentrations of tBMA were maintained at $5 \mathrm{mg} / \mathrm{mL}$ in $\mathrm{D}_{2} \mathrm{O}$ for all analyses. The complexation between $M \beta C D$ and $t B M A$ was previously reported by Madison and Long $^{3}$ for the purpose of free radical polymerization in aqueous phase. However, different to the method of direct complexation in water in this study, their complex was prepared by dissolving the $t B M A$ and $M B C D$ in chloroform and the evaporation of solvent. In this study, the complexation between $M B C D$ and $t B M A$ was examined by visual appearance and ${ }^{1} H N M R$. MBCD and tBMA were mixed in $\mathrm{D}_{2} \mathrm{O}$ with molar ratio of $1: 1,1: 2,1: 5$ and $0: 1$, turbidity and ${ }^{1} \mathrm{H} N M R$ spectrum were obtained after 10 min-sonication. As shown in Figure S3, the turbidity of the solution decreased with higher added amount of $M \beta C D$, indicated the better solubility of tBMA in $D_{2} O$. The turbidity of suspension with 1:1 ratio of MBCD: $t B M A$ was only 1.06 NTU, which is distinct from the other groups. The ${ }^{1} \mathrm{H}$ NMR spectra (Figure S3) support this observation, for the unstable tBMA in $\mathrm{D}_{2} \mathrm{O}$ emulsion (0:1), most tBMA presented in the oil phase. With increased amount of added $M B C D$, the integration of peaks of $t B M A$ in oil phase decreased, whereas those in aqueous phase increased. For MBCD: $t B M A$ $=1: 1$, only aqueous tBMA peaks were observed. Same experiments were conducted to confirm the complexation between $M \beta C D /$ st and $M \beta C D / t B A$ as shown in Figure S4 and S5. 


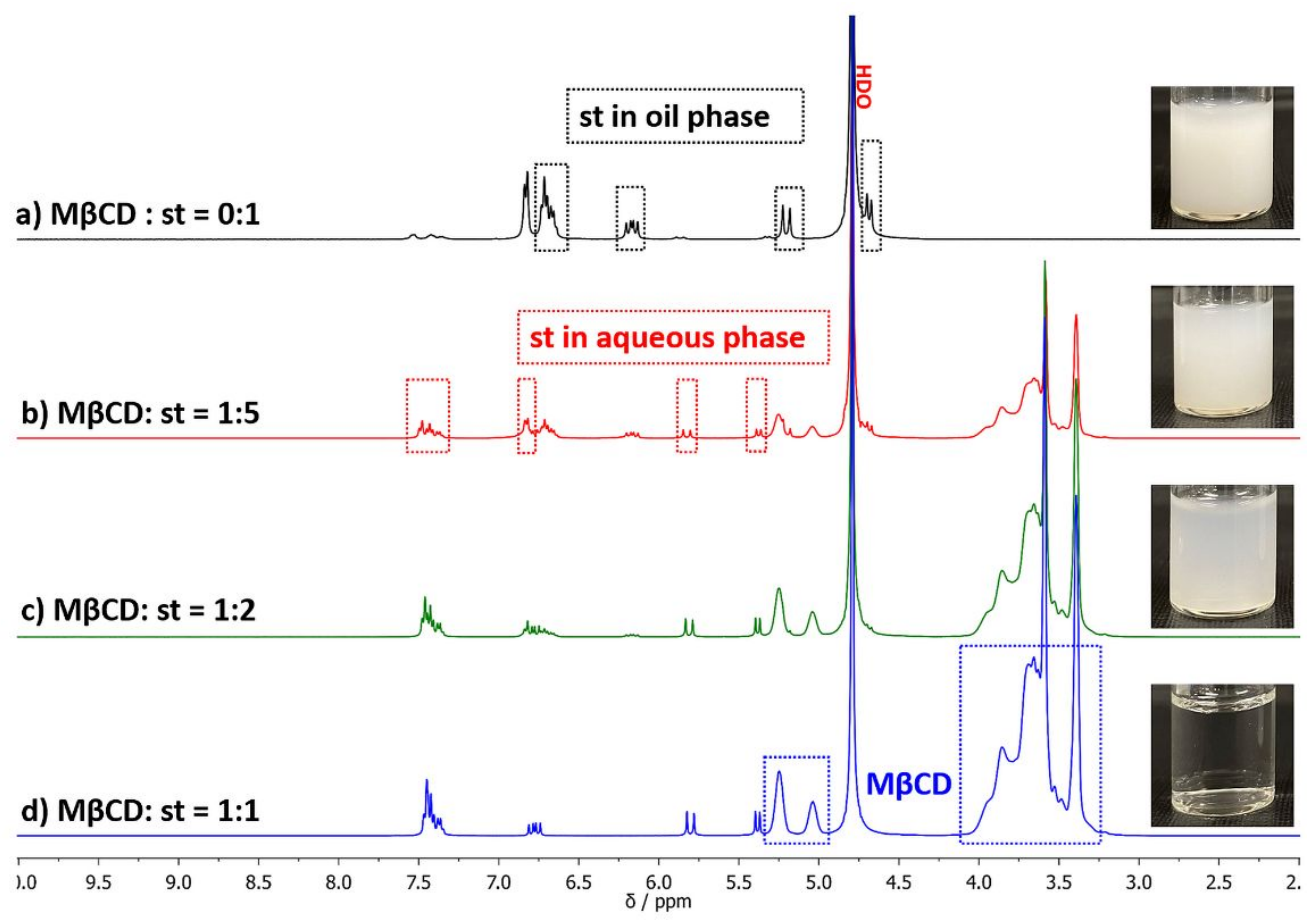

Figure S4. ${ }^{1} \mathrm{H}$ NMR spectra $\left(400 \mathrm{MHz}, \mathrm{D}_{2} \mathrm{O}\right)$ and digital photo of $\mathrm{M} \beta \mathrm{CD} / \mathrm{st}$ in $\mathrm{D}_{2} \mathrm{O}$ with $\mathrm{M} \beta \mathrm{CD}$ : st molar ratio of (a) 0:1, (b) 1:5, (c) 1:2 and (d) $1: 1$ (5 mg st/mL $\mathrm{D}_{2} \mathrm{O}$ ).

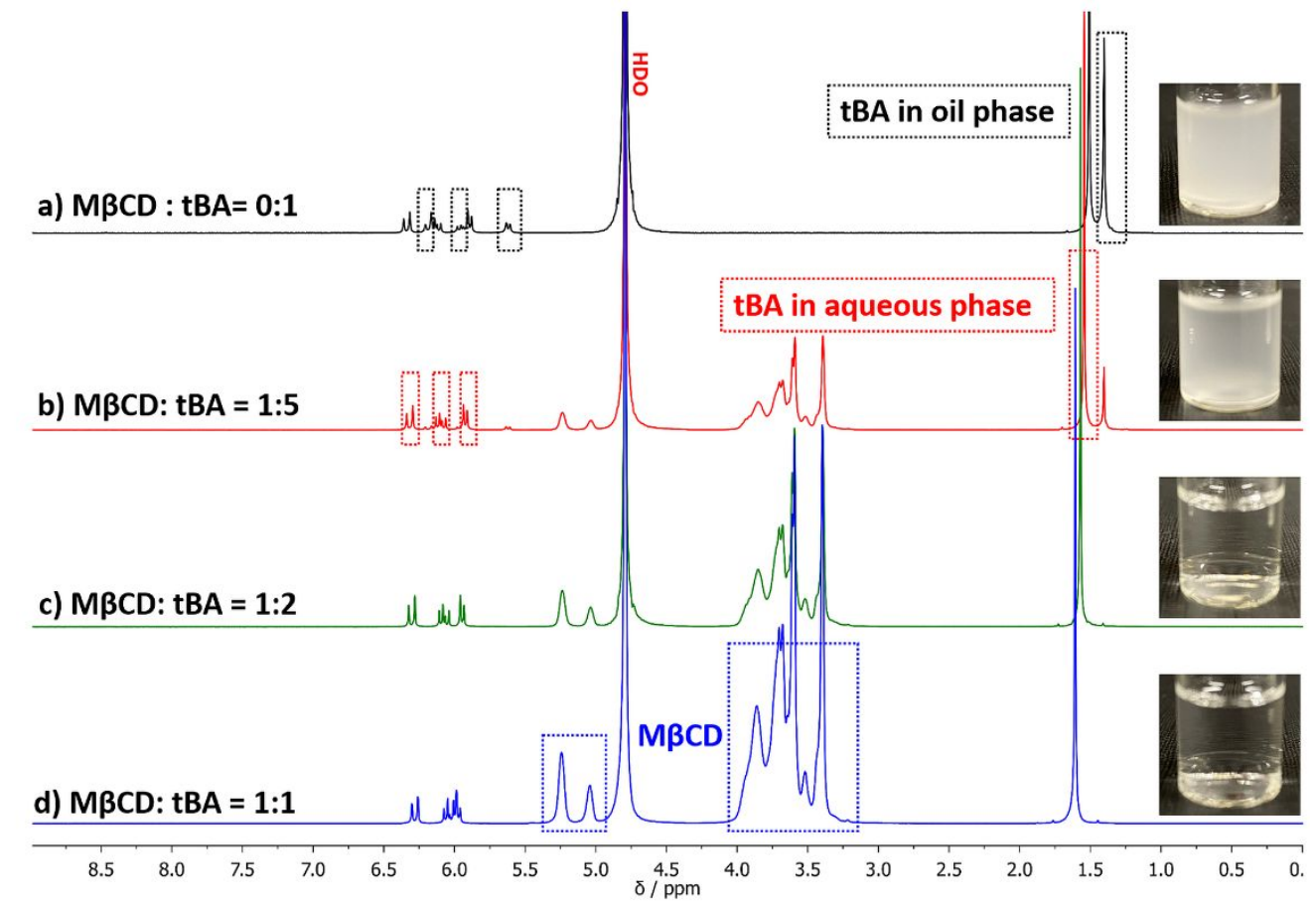

Figure S5. ${ }^{1} \mathrm{H}$ NMR spectra ( $400 \mathrm{MHz}, \mathrm{D}_{2} \mathrm{O}$ ) and digital photo of $\mathrm{M} \beta \mathrm{CD} / \mathrm{tBA}$ in $\mathrm{D}_{2} \mathrm{O}$ with $\mathrm{M} \beta \mathrm{CD}$ : tBA molar ratio of (a) 0:1, (b) 1:5, (c) 1:2 and (d) $1: 1$ (5 mg tBA/mL $\mathrm{D}_{2} \mathrm{O}$ ). 


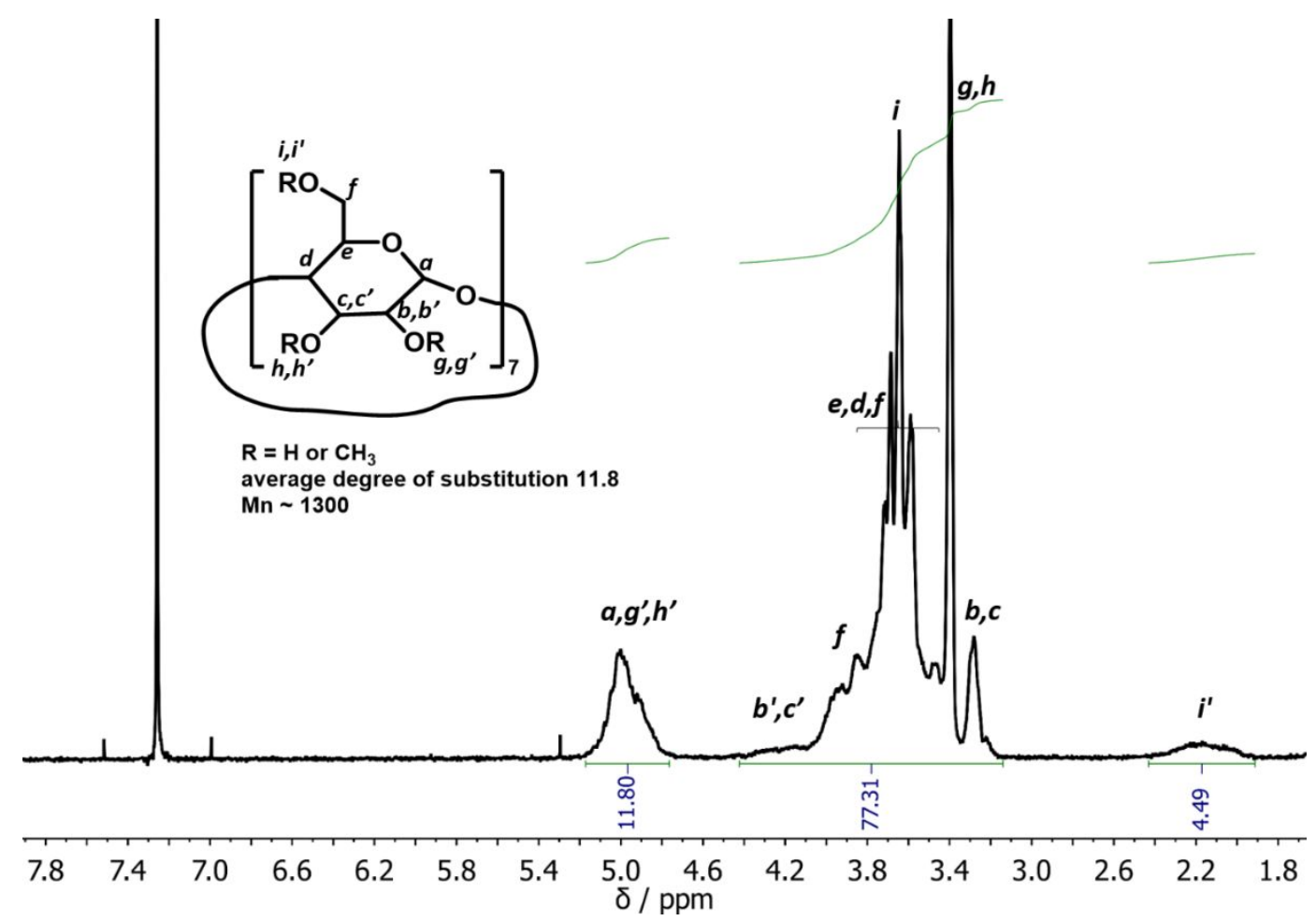

Figure S6. ${ }^{1} \mathrm{H}$ NMR spectrum $\left(400 \mathrm{MHz}, \mathrm{CDCl}_{3}\right)$ of randomly methylated- $\beta$-cyclodextrin

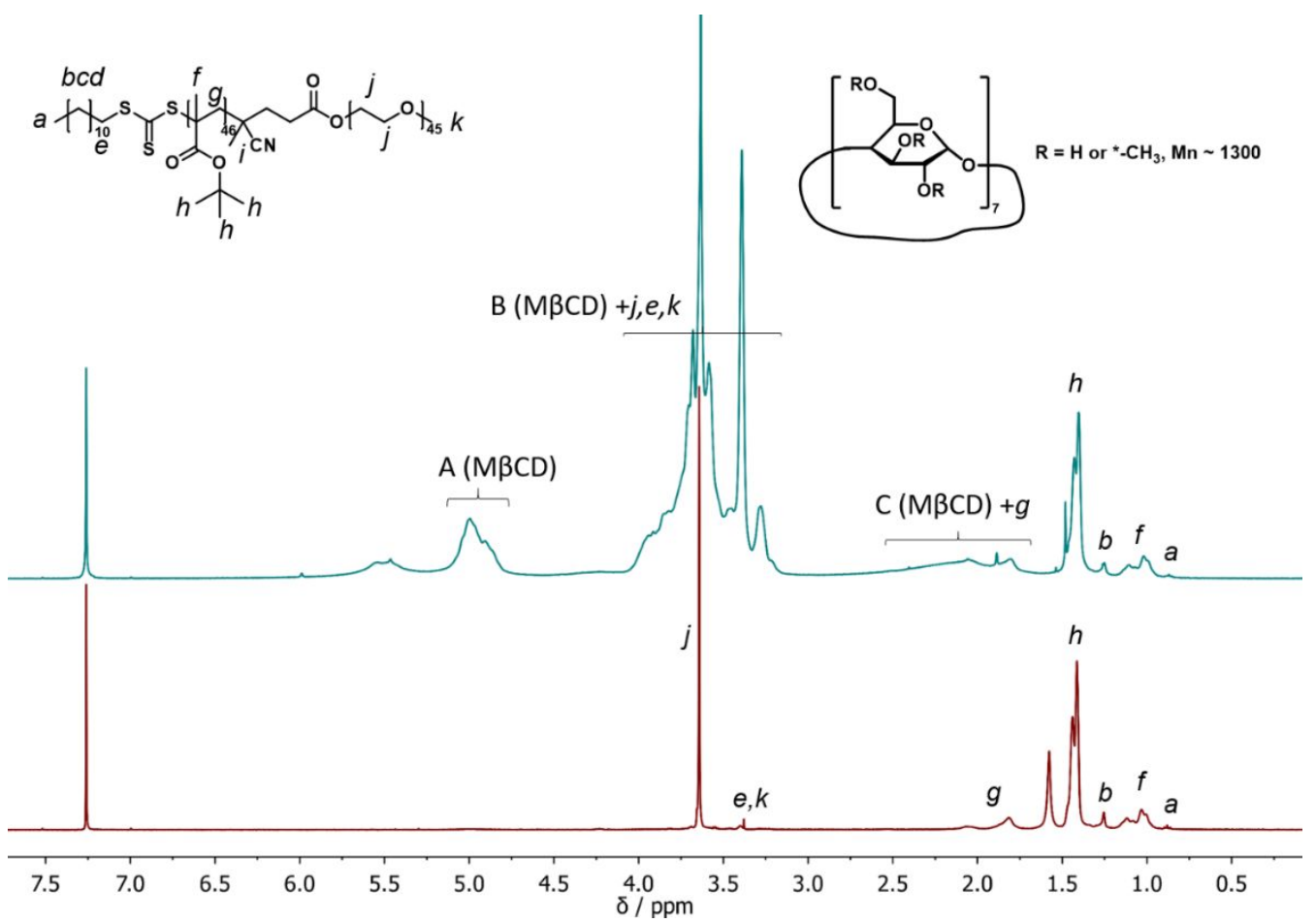

Figure S7. ${ }^{1} \mathrm{H}$ NMR spectra ( $400 \mathrm{MHz}, \mathrm{CDCl}_{3}$ ) of $\mathrm{PEG}_{45}-b-\mathrm{PtBMA}_{46}$ suspension before (above) and after (below) dialysis. Almost all $M \beta C D$ were removed after dialysis. Similar result was obtained for the suspension of $\mathrm{PEG}_{113}-b-\mathrm{PtBMA}_{97}$ before and after dialysis.

DP of PtBMA calculated form crude suspension = (integration of $\mathrm{f}$ )/ (integration of $\mathrm{A}) \times$ $[\mathrm{M} \beta \mathrm{CD}] /[$ macro-RAFT $] \times 11.8 / 3$

DP of PtBMA calculated from suspension after dialysis $=($ integration of $\mathrm{f}) /($ integration of $\mathrm{j}) \times$ repeating unit of PEG $\times 4 / 3$ 


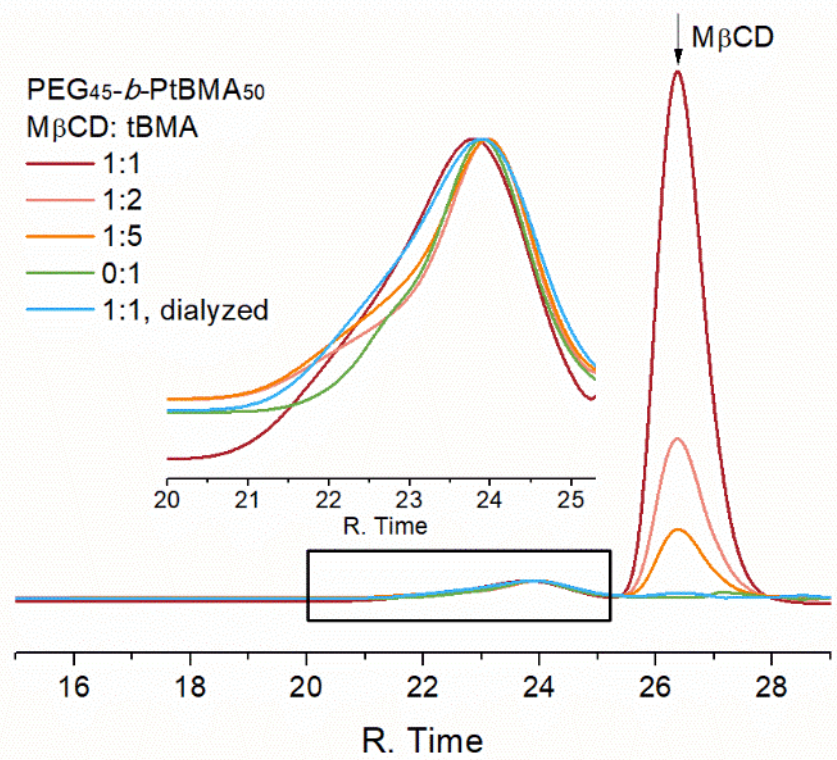

Figure S8. GPC traces of synthesized $\mathrm{PEG}_{45}-b-\mathrm{PtBMA}_{\mathrm{n}}(\mathrm{n}=44-46)$ suspension with $\mathrm{M} \beta C D$ : tBMA molar ratio of $0: 1,1: 5,1: 2$ and 1:1, and 1:1 with $M \beta C D$ being removed by dialysis (DMF as eluent, PMMA standards).

a)

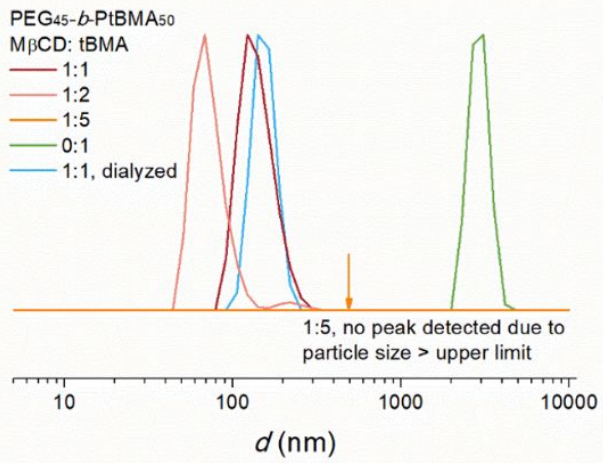

b)

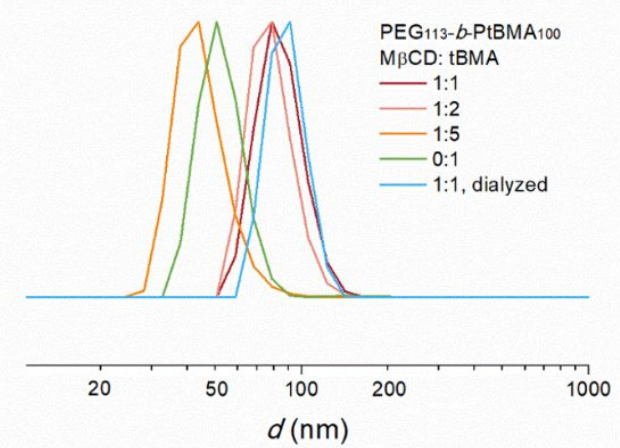

Figure S9. DLS curves of (a) $\mathrm{PEG}_{45}-b-\mathrm{PtBMA}_{50}$ and (b) $\mathrm{PEG}_{113}-b-\mathrm{PtBMA}_{100}$ suspension with $\mathrm{M} \beta \mathrm{CD}$ : tBMA molar ratio of $0: 1,1: 5,1: 2$ and $1: 1$, and $1: 1$ with $M \beta C D$ being removed by dialysis. 


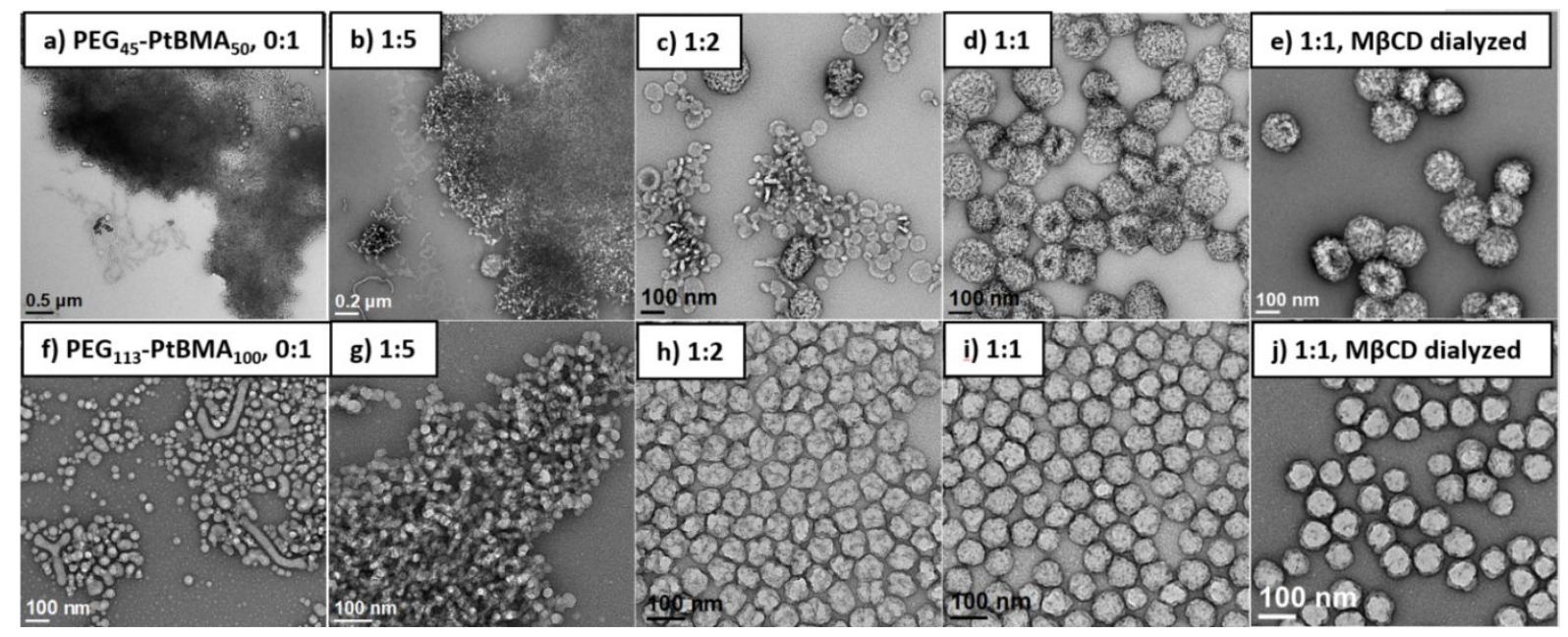

Figure S10. Representative TEM images of synthesized (a-e) $\mathrm{PEG}_{45}-b-\mathrm{PtBMA}_{50}$ and (f-j) $\mathrm{PEG}_{113}-b-$ $\mathrm{PtBMA}_{100}$ with various molar ratio of $\mathrm{M} \beta \mathrm{CD}$ : $\mathrm{tBMA}$ and after removal of $\mathrm{M} \beta \mathrm{CD}$ by dialysis.

Table S2. Characterization data of PEG- $b$-PtBMA with various molar ratio of M $\beta C D$ : tBMA.

\begin{tabular}{|c|c|c|c|c|c|c|c|}
\hline Entry & $\mathrm{M} \beta \mathrm{CD}: \mathrm{tBMA}$ & $\mathrm{DP}^{\mathrm{a}}$ & $\begin{array}{l}M_{\mathrm{n}, \mathrm{NMR}}^{\mathrm{b}} \\
(\mathrm{kg} / \mathrm{mol})\end{array}$ & $\begin{array}{l}M_{\mathrm{n}, \mathrm{GPC}} \\
(\mathrm{kg} / \mathrm{mol})\end{array}$ & 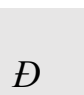 & $\begin{array}{l}Z_{\mathrm{a}, \mathrm{DLS}} \\
(\mathrm{nm})\end{array}$ & $\mathrm{PDI}_{\mathrm{DL}}$ \\
\hline \multicolumn{8}{|c|}{ Targeting $\mathrm{PEG}_{45}-b-\mathrm{PtBMA} \mathrm{A}_{50}$} \\
\hline 1 & $0: 1$ & 44 & 8.7 & 6.9 & 1.07 & 2906 & 0.23 \\
\hline 2 & $1: 5$ & 46 & 8.9 & 7.3 & 1.11 & 9239 & 0.78 \\
\hline 3 & $1: 2$ & 45 & 8.8 & 7.2 & 1.10 & 561.8 & 0.71 \\
\hline 4 & $1: 1$ & 46 & 8.9 & 7.8 & 1.12 & 159.7 & 0.01 \\
\hline $4 a$ & 1:1 M $\beta C D$ dialyzed & 46 & 8.9 & 7.3 & 1.10 & 159.8 & 0.07 \\
\hline \multicolumn{8}{|c|}{ Targeting $\mathrm{PEG}_{113}-b-\mathrm{PtBMA} \mathrm{A}_{100}$} \\
\hline 5 & $0: 1$ & 87 & 17.8 & 16.2 & 1.15 & 109.0 & 0.40 \\
\hline 6 & $1: 5$ & 95 & 18.9 & 17.7 & 1.24 & 66.7 & 0.26 \\
\hline 7 & $1: 2$ & 94 & 18.8 & 17.3 & 1.17 & 89.8 & 0.10 \\
\hline 8 & $1: 1$ & 97 & 19.2 & 18.0 & 1.20 & 93.6 & 0.02 \\
\hline $8 \mathrm{a}$ & 1:1 M $\beta C D$ dialyzed & 97 & 19.2 & 17.3 & 1.21 & 93.3 & 0.01 \\
\hline
\end{tabular}

The complexation study suggested the optimum ratio of $M B C D$ : tBMA is 1:1 to make water-soluble complex. The impact of $M \beta C D$ : $t B M A$ ratio on the dispersion polymerization of self-assembly was further studied. This was investigated by dispersion polymerization of PEG ${ }_{45}-C D T P A$ and PEG $113^{-}$ CDTPA with tBMA at different ratio of $M B C D: t B M A=0: 1,1: 5,1: 2$ and $1: 1$ (target DP 50 and 100 respectively). The suspensions at the end of $16 \mathrm{~h}$ were analyzed (Table S2). The various ratio of M $B C D$ : tBMA did not have obvious impact on the degree of polymerization and the molecular weight (Figure S8). However, the stability of nanoparticles suspension decreased with the reduced amount of $M \beta C D$, as judged by observation and DLS (Figure S9). For the groups with MBCD: tBMA ratio less than 1:1 (Table S2, entry 1-3 and 5-7), PDI is higher than 0.1, which indicated broad size distributions of the suspensions. Some peculiarly large $Z_{a}$ diameters (Table $S 2$, entry 1,2) were obtained due to poor sample quality, which were generated from the agglomeration of the unstable polymer particles in water. The 
reason for particle instability is that when $M \beta C D$ is added at a ratio of less than 1:1, tBMA is presented as a water-immiscible monomer instead of a water-soluble complex and undergoes emulsion polymerization in water. In the early stage of polymerization, the chemical potential of the monomer droplets is higher than that of the monomer in the first nucleated particles formed by oligomers. As a result, a large amount of the monomer would transfer from the droplets to these particles, leading to a large increase in size and colloidal instability. This phenomenon is known as the superswelling effect. ${ }^{4}$ For the group with 1:1 ratio of $M \beta C D$ : $t B M A$ (Table $S 2$, entry 4,8), the majority of $t B M A$ is complexed with $M B C D$, and thus suppress the transfer of $t B M A$ into particles and result in stable nanoparticles with low PDI. TEM analysis strongly demonstrated the distinct difference between the morphologies of copolymer nanoparticles with different ratio of $M \beta C D$ : $t B M A$. The ones with $M \beta C D$ : $t B M A=1: 1$ were uniform and monodispersed nano-objects as shown in Figure S10d and S10i, whereas the group with $M \beta C D: t B M A=1: 2$ (Figure S10c, S10h), a mixture of different morphologies was found. Mixture and agglomerates were observed for groups with $M \beta C D: t B M A=1: 5$ and 0:1 (Figure S10a, $b, f, g$ ). These results demonstrate that $M \beta C D$ : monomer ratio has an impact on the monomer solubility, which determines whether the process undergoes emulsion or dispersion polymerization. In order to synthesize stable nanoparticles by dispersion polymerization, the ratio of $M \beta C D$ : monomer was maintained at 1:1.

During polymerization, the increased steric hindrance and the strong hydrophobic interaction of neighboring tert-butyl moieties competes with the interaction of $M \beta C D,{ }^{5}$ resulting in the dissociation between $M \beta C D$ and PtBMA. From this point of view, $M \beta C D$ does not complex with the self-assembled particles, and can be removed without changing morphology of particles. This was examined by removing $M \beta C D$ from $\mathrm{PEG}_{45}-\mathrm{PtBMA}_{46}$ and $\mathrm{PEG}_{113}-\mathrm{PtBM} A_{97}$ suspension by dialysis against $\mathrm{DI} \mathrm{H}_{2} \mathrm{O}$ for two days. Almost all MBCD was removed according to ${ }^{1} H$ NMR spectra (Figure S7). The DP of PEG-b-PtBMA polymers remained the same after dialysis as calculated by NMR, and the molecular weights measured by GPC (Figure S8) were almost unchanged as well. As judged by DLS (Table S2, entry $4 a$ and $8 a$ ), the particles also remained stable after dialysis and were close in size to the particles before dialysis. The morphology of particles remained unchanged as judged by TEM (Figure S10e and S10j). These results agree with the findings of Yuan et al. 's study, in which CD unthreaded from resulted PS chains during polymerization. ${ }^{6}$ The $M \beta C D$ unthreaded from polymer chains is freely soluble in water and can be removed for reuse. A simpler approach would be to complex free $M B C D$ directly with the monomer of the third block for further polymerization without removing it, as in this study. 

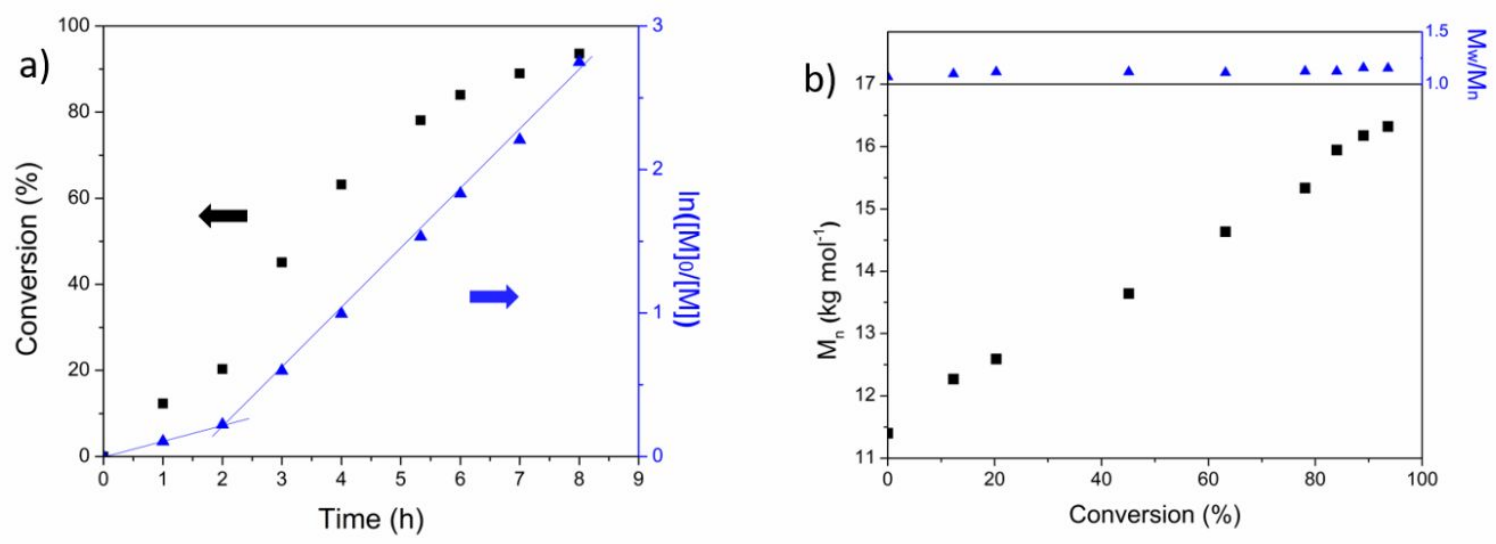

Figure S11. (a) $\ln \left([\mathrm{M}]_{0} /[\mathrm{M}]\right)$ and conversion $v s$. time and (b) molecular weight and $Ð v s$. conversion plots for the polymerization of $\mathrm{M} \beta \mathrm{CD} / \mathrm{st}$ in water at $70{ }^{\circ} \mathrm{C}$. (Solid content $=3 \mathrm{wt} \%$, [ACVA]/[PEG $13^{-}$ $\mathrm{CDTPA}] /[\mathrm{st}] /[\mathrm{M} \beta \mathrm{CD}]=0.3 / 1 / 100 / 100)$

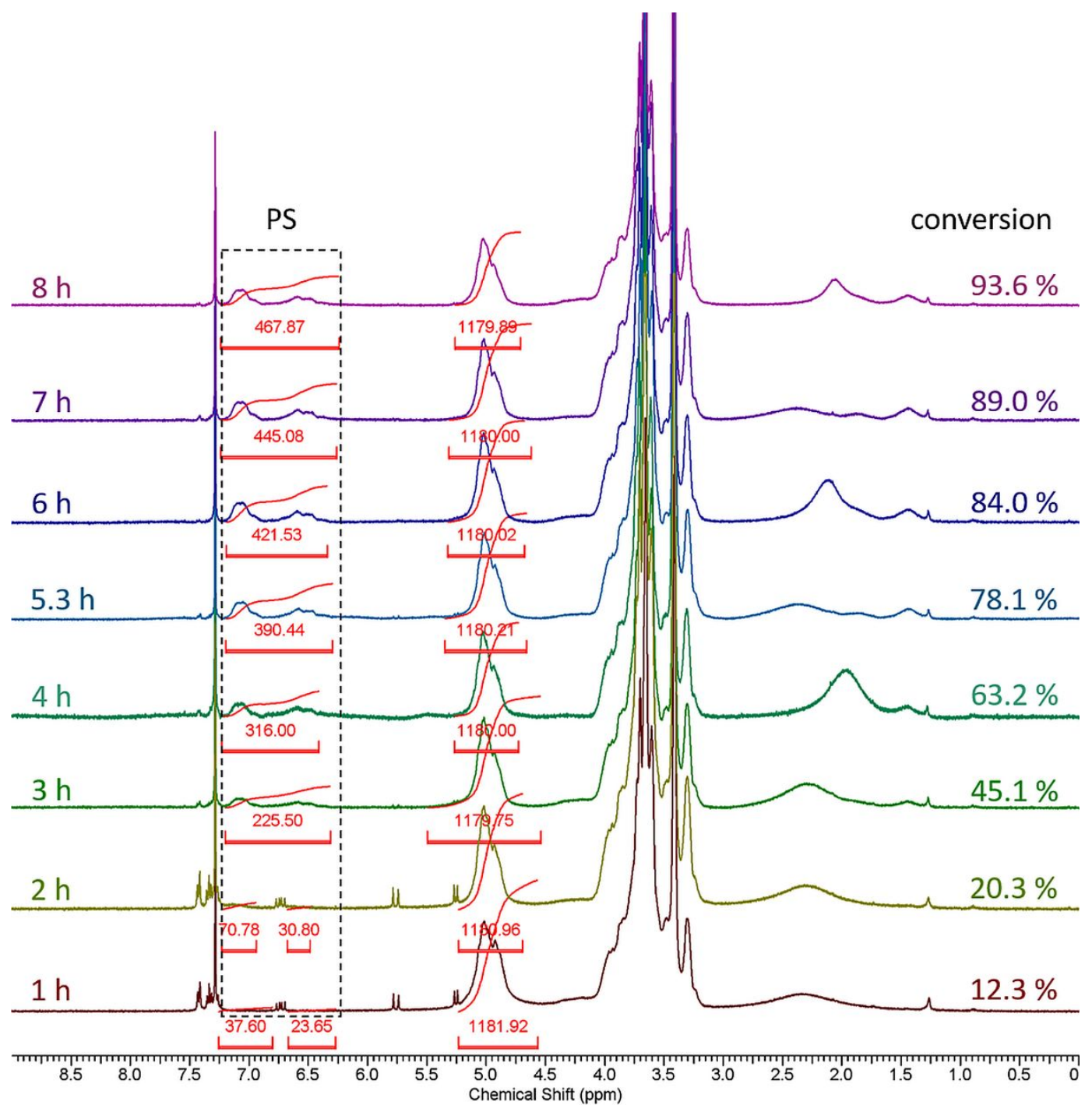

Figure S12. ${ }^{1} \mathrm{H}$ NMR spectra $\left(400 \mathrm{MHz}, \mathrm{CDCl}_{3}\right)$ of suspensions collected at specific time points during dispersion polymerization of $\mathrm{M} \beta \mathrm{CD} / \mathrm{st}$ (targeting $\mathrm{PEG}_{113}-b-\mathrm{PS}_{100}$ ). DP of PS $=[1 / 5 \times$ integration of PS $(7.2-6.3 \mathrm{ppm})] /[1 /(11.8 \times 100) \times$ integration of $\mathrm{M} \beta \mathrm{CD}(5.3-4.7 \mathrm{ppm})]$. Conversion estimated by DP of $\mathrm{PS} / 100 \times 100 \%$. 


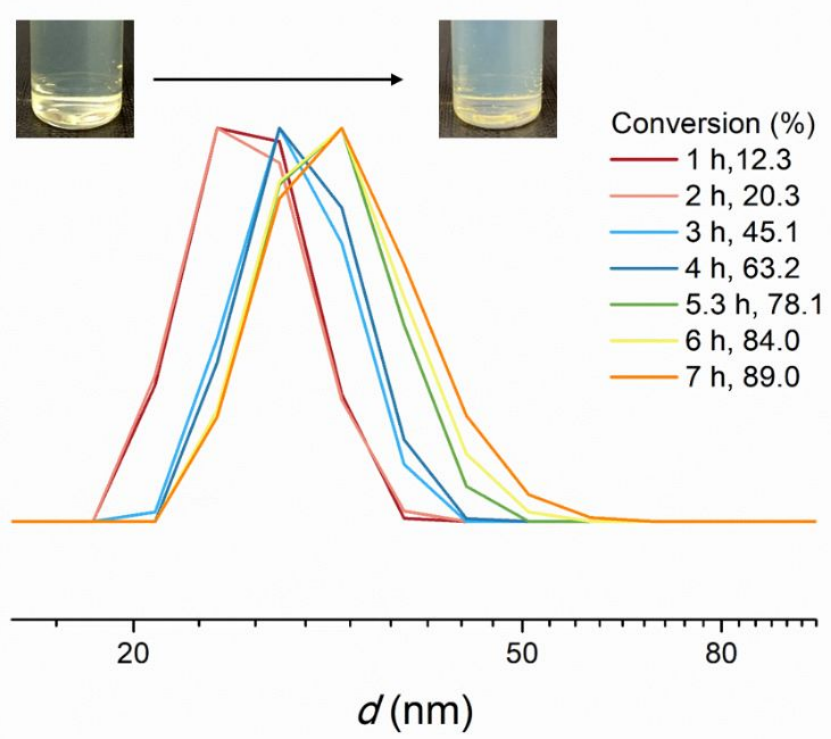

Figure S13. DLS curves of suspensions collected at specific time points during dispersion polymerization of $\mathrm{M} \beta \mathrm{CD} / \mathrm{st}$ (targeting $\mathrm{PEG}_{113}-b-\mathrm{PS}_{100}$ ) with increasing conversion. Inset photos show the comparison of cloudiness before and after PISA.

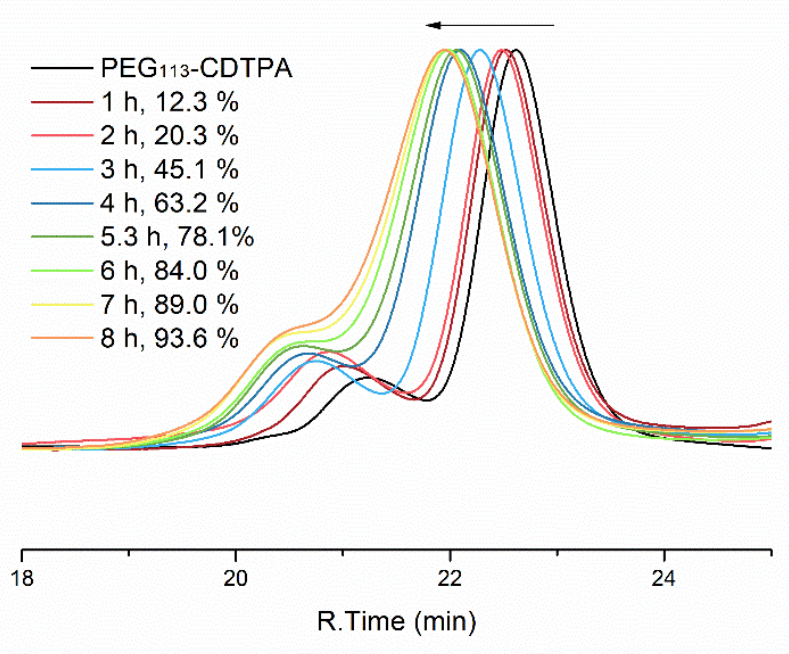

Figure S14. GPC traces of $\mathrm{PEG}_{113}-\mathrm{CDTPA}$ and $\mathrm{PEG}_{113}-b-\mathrm{PS}_{\mathrm{x}}$ collected at specific time points during dispersion polymerization of $\mathrm{M} \beta \mathrm{CD} / \mathrm{st}$ (targeting $\mathrm{PEG}_{113}-b-\mathrm{PS}_{100}$ ) (DMF as eluent, PMMA standards). The bimodal curves are because of the impurity from commercial $P E G_{113}$ (Figure S2). 


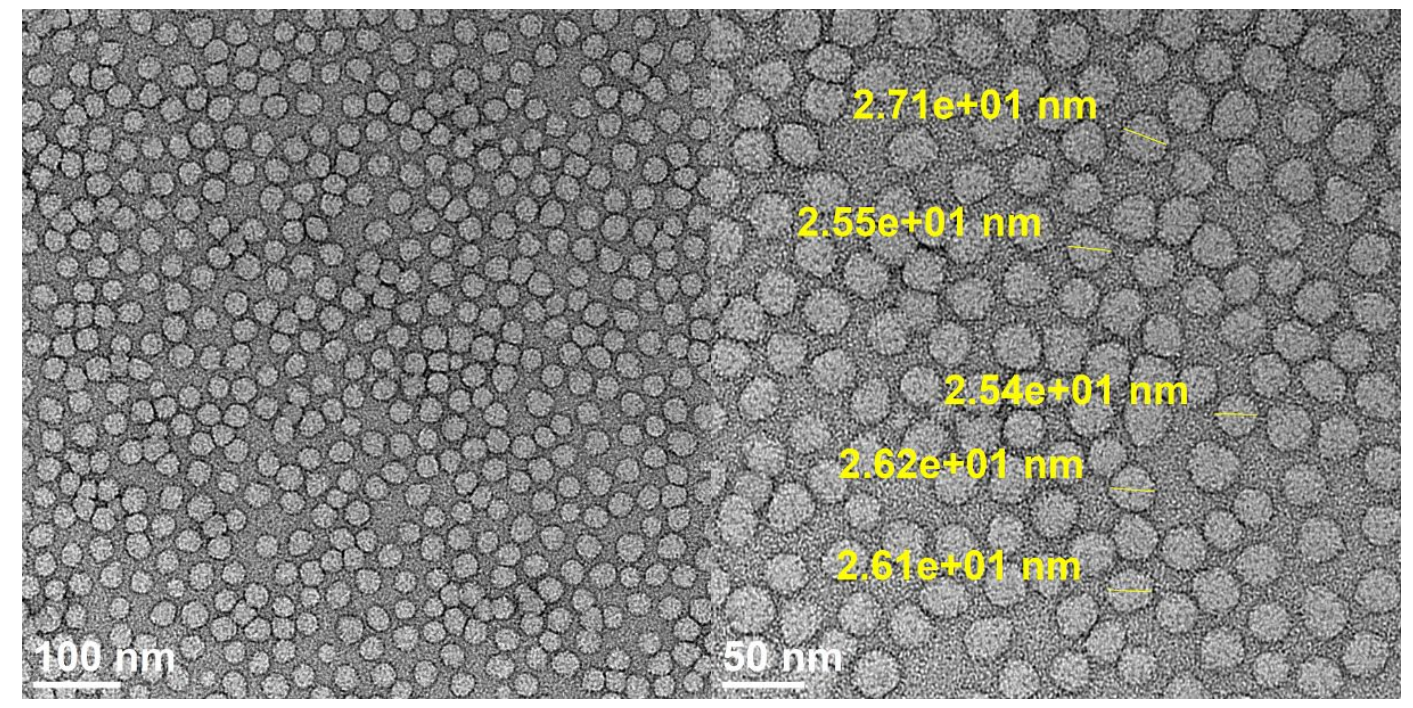

Figure S15. TEM images of $\mathrm{E}_{113} \mathrm{~S}_{100}$ synthesized in water with $1: 1 \mathrm{M} \beta \mathrm{CD} / \mathrm{st}$ at $50{ }^{\circ} \mathrm{C}$ (using 2,2'Azobis[2-(2-imidazolin-2-yl)propane]dihydrochloride (VA-044) as initiator). Average size of spherical nanoparticles measured as $26.6 \pm 2.7 \mathrm{~nm}$ (by measuring $>100$ random particles).
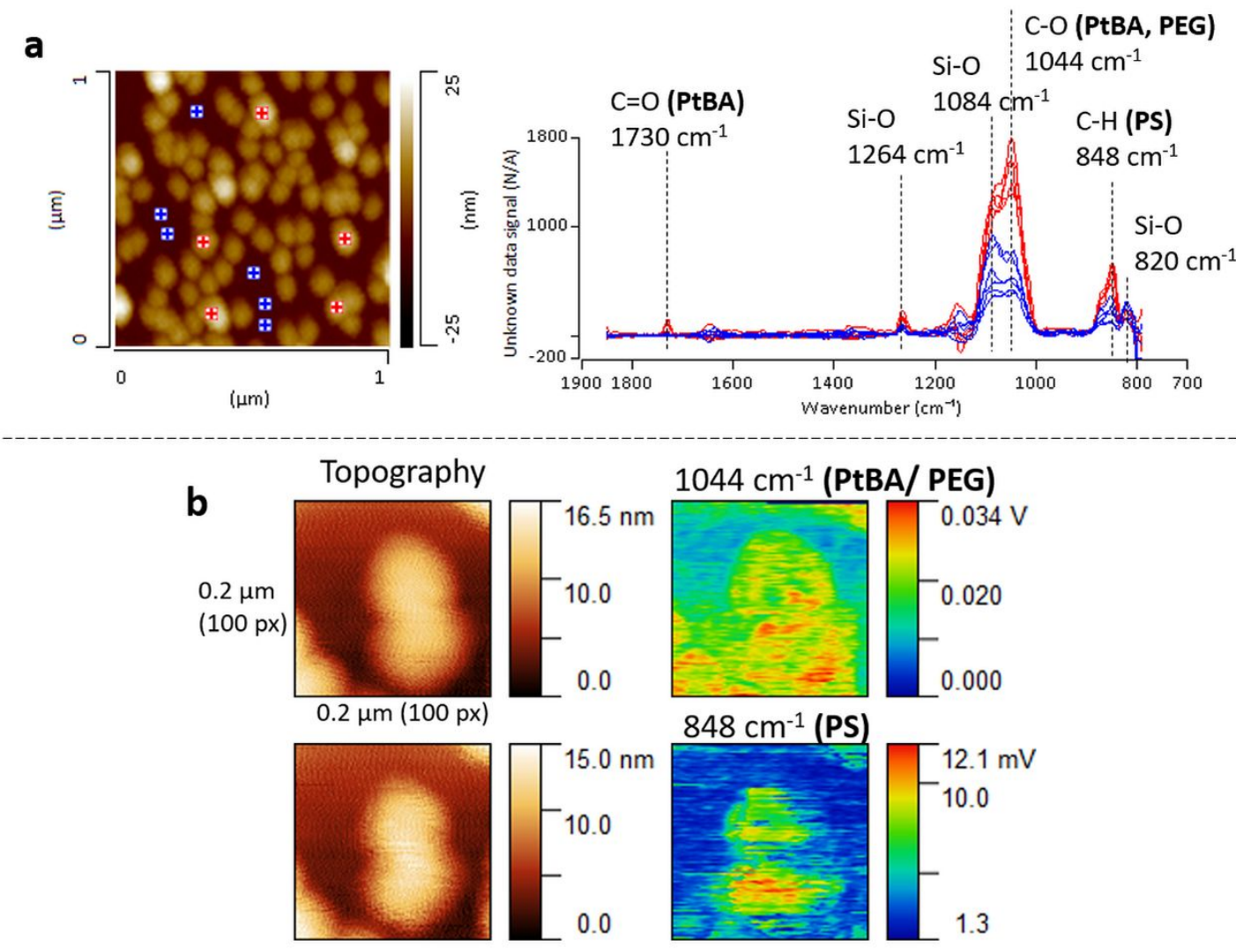

Figure S16. (a) IR spectra collected from background and particles of $E_{113} S_{100} T_{80}$ colloids. (No signal detected between the $1600-1400 \mathrm{~cm}^{-1}$ wavenumber due to IR chip fault. Other wavenumbers were not affected.) (b) Topography maps and IR signal maps of $E_{113} S_{100} T_{80}$ colloids obtained at $1044 \mathrm{~cm}^{-1}$ and $848 \mathrm{~cm}^{-1}$ wavenumbers. 


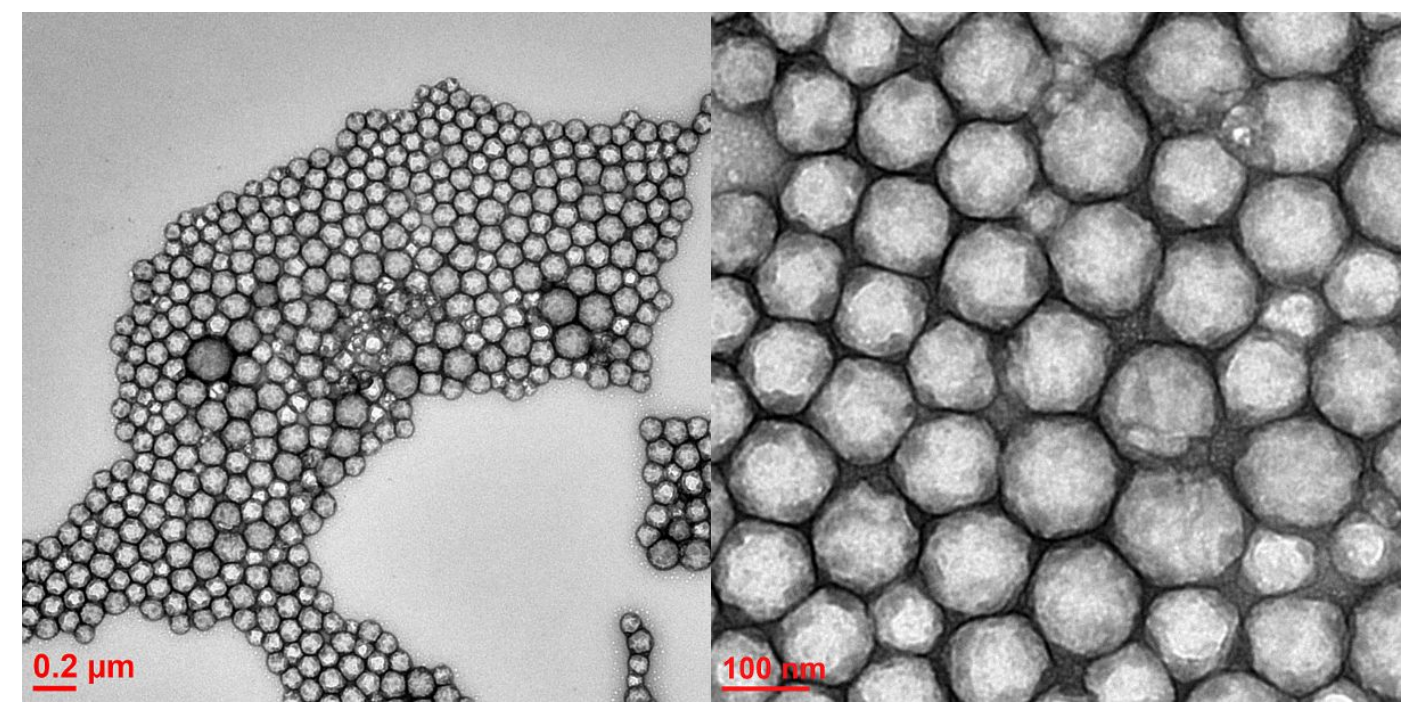

Figure S17. TEM images of $E_{113} S_{100} T_{200}$ synthesized in water without MBCD.

Table S3. Summary of ES colloidal atoms and EST colloidal molecules.

\begin{tabular}{|l|l|l|l|l|l|l|l|l|}
\hline Entry & Polymer & $V_{\mathrm{C}} / V_{\mathrm{B}}^{\mathrm{b}}$ & $\begin{array}{l}M_{\mathrm{n}, \mathrm{NMR}}{ }^{\mathrm{c}} \\
(\mathrm{kg} / \mathrm{mol})\end{array}$ & $\begin{array}{l}M_{\mathrm{n}, \mathrm{GPC}} \\
(\mathrm{kg} / \mathrm{mol})\end{array}$ & $Ð$ & $\begin{array}{l}Z_{\mathrm{a}, \mathrm{DLS}} \\
(\mathrm{nm})\end{array}$ & PDI $_{\text {DLS }}$ & $N_{\text {avg }}$ \\
\hline I & $\mathrm{E}_{113} \mathrm{~S}_{100}$ & 0 & 15.8 & 18.1 & 1.19 & 37.7 & 0.04 & 1 \\
\hline II & $\mathrm{E}_{113} \mathrm{~S}_{200}$ & 0 & 26.2 & 23.0 & 1.31 & 43.7 & 0.10 & 1 \\
\hline III & $\mathrm{E}_{113} \mathrm{~S}_{100} \mathrm{~T}_{80}$ & 1.03 & 26.0 & 20.8 & 1.26 & 59.1 & 0.07 & $2.22 \pm 0.55$ \\
\hline IV & $\mathrm{E}_{113} \mathrm{~S}_{100} \mathrm{~T}_{120}$ & 1.55 & 31.2 & 19.6 & 1.31 & 62.4 & 0.08 & $3.18 \pm 0.64$ \\
\hline V & $\mathrm{E}_{113} \mathrm{~S}_{100} \mathrm{~T}_{250}$ & 3.23 & 47.9 & 20.7 & 1.39 & 76.6 & 0.04 & $3.97 \pm 0.60$ \\
\hline VI & $\mathrm{E}_{113} \mathrm{~S}_{200} \mathrm{~T}_{89}$ & 0.58 & 37.6 & 24.0 & 1.31 & 66.4 & 0.14 & $1.67 \pm 0.61$ \\
\hline VII & $\mathrm{E}_{113} \mathrm{~S}_{200} \mathrm{~T}_{235}$ & 1.52 & 56.3 & 25.9 & 1.39 & 108.5 & 0.04 & $>6$ \\
\hline
\end{tabular}

${ }^{\mathrm{a} D P}$ of polymers were calculated from ${ }^{1} \mathrm{H}$ NMR.

${ }^{\mathrm{b}} V_{\mathrm{C}} / V_{\mathrm{B}}$ is the volume ratio of block $\mathrm{C}$ and $\mathrm{B}$ of the $\mathrm{ABC}$ triblock terpolymer, which is $\mathrm{PtBA} / \mathrm{PS}$ in this case.

$$
\frac{V_{C}}{V_{B}}=\frac{M_{C} / \rho_{C}}{M_{B} / \rho_{B}}=\frac{D P_{C} M_{\text {monomer } C} \times \rho_{B}}{D P_{B} M_{\text {monomer } B} \times \rho_{C}}
$$

where $\rho_{\mathrm{B}}$ is the density of PS $\left(1.05 \mathrm{~g} / \mathrm{cm}^{3}\right)$ and $\rho_{\mathrm{C}}$ is the density of PtBA $\left(1.00 \mathrm{~g} / \mathrm{cm}^{3}\right) . M_{\text {monomer B }}$ and $M_{\text {monomer } \mathrm{C}}$ are the molecular weights of styrene and tert-butyl acrylate.

${ }^{\mathrm{c}} M_{\mathrm{n}, \mathrm{NMR}}=M_{\mathrm{n}, \text { macro-RAFT }}+\mathrm{DP}_{\mathrm{PS}} \times M_{\mathrm{n}, \mathrm{st}}+\mathrm{DP}_{\mathrm{PtBA}} \times M_{\mathrm{n}, \mathrm{BBA}}$

${ }^{\mathrm{d}}$ Average valence $\left(N_{\text {avg }}\right)$ of EST CMs is measured by counting $>500$ particles in a TEM image.

$$
N_{\text {avg }}=\sum_{i=1}^{n} N_{i} / n, \sigma=\sqrt{\frac{\sum_{i=1}^{n}\left(N_{i}-N_{\text {avg }}\right)^{2}}{n}}
$$

where $n$ is the total number of counted particles, $\sigma$ is the standard deviation of the counted particles, $N_{\mathrm{i}}$ is the valence number of the $i^{\text {th }}$ particle. 
Table S4. Kinetic study of seeded dispersion polymerization of MBCD/tBA complex $\left(E_{113} S_{100}\right.$ to $E_{113} S_{100} T_{x}$, targeting $\left.X=200\right)$.

\begin{tabular}{|l|l|l|l|l|l|l|l|l|l|l|}
\hline Entry & $\begin{array}{l}\text { Time } \\
(\mathrm{h})\end{array}$ & Polymer & $V_{\mathrm{C}} / V_{\mathrm{B}}$ & $\begin{array}{l}\text { Conv. } \\
(\%)^{\mathrm{b}}\end{array}$ & $\begin{array}{l}M_{\mathrm{n}, \mathrm{NMR}} \\
(\mathrm{kg} / \mathrm{mol})\end{array}$ & $\begin{array}{l}M_{\mathrm{n}, \mathrm{GPC}} \\
(\mathrm{kg} / \mathrm{mol})\end{array}$ & $\nexists$ & $Z_{\mathrm{a}, \mathrm{DLS}}(\mathrm{nm})$ & $\mathrm{PDI}_{\mathrm{DLS}}$ & $N_{\text {avg }}$ \\
\hline 1 & 1 & $\mathrm{E}_{113} \mathrm{~S}_{100} \mathrm{~T}_{31}$ & 0.40 & 15.6 & 19.8 & 18.9 & 1.19 & 36.2 & 0.10 & $1.02 \pm 0.12$ \\
\hline 2 & 2 & $\mathrm{E}_{113} \mathrm{~S}_{100} \mathrm{~T}_{52}$ & 0.67 & 26.0 & 22.5 & 19.9 & 1.21 & 46.2 & 0.16 & $-^{*}$ \\
\hline 3 & 3 & $\mathrm{E}_{113} \mathrm{~S}_{100} \mathrm{~T}_{70}$ & 0.91 & 35.1 & 24.8 & 20.2 & 1.25 & 56.9 & 0.20 & $2.39 \pm 0.53$ \\
\hline 4 & 4 & $\mathrm{E}_{113} \mathrm{~S}_{100} \mathrm{~T}_{88}$ & 1.14 & 44.2 & 27.1 & 20.9 & 1.26 & 58.5 & 0.18 & $-^{*}$ \\
\hline 5 & 5 & $\mathrm{E}_{113} \mathrm{~S}_{100} \mathrm{~T}_{99}$ & 1.28 & 49.5 & 28.5 & 21.5 & 1.28 & 60.4 & 0.11 & $2.88 \pm 0.75$ \\
\hline 6 & 6 & $\mathrm{E}_{113} \mathrm{~S}_{100} \mathrm{~T}_{107}$ & 1.39 & 53.6 & 29.6 & 21.9 & 1.31 & 61.0 & 0.20 & $-^{*}$ \\
\hline 7 & 7 & $\mathrm{E}_{113} \mathrm{~S}_{100} \mathrm{~T}_{117}$ & 1.51 & 58.5 & 30.8 & 22.1 & 1.28 & 63.7 & 0.11 & $3.09 \pm 0.51$ \\
\hline 8 & 8 & $\mathrm{E}_{113} \mathrm{~S}_{100} \mathrm{~T}_{127}$ & 1.65 & 63.7 & 32.1 & 22.4 & 1.30 & 62.4 & 0.08 & $-^{*}$ \\
\hline 9 & 9 & $\mathrm{E}_{113} \mathrm{~S}_{100} \mathrm{~T}_{134}$ & 1.73 & 66.8 & 32.9 & 22.6 & 1.31 & 62.9 & 0.17 & $3.22 \pm 0.68$ \\
\hline 10 & 10 & $\mathrm{E}_{113} \mathrm{~S}_{100} \mathrm{~T}_{143}$ & 1.85 & 71.6 & 34.2 & 22.9 & 1.30 & 62.4 & 0.05 & $-^{*}$ \\
\hline 11 & 16 & $\mathrm{E}_{113} \mathrm{~S}_{100} \mathrm{~T}_{163}$ & 2.10 & 81.4 & 36.7 & 23.3 & 1.33 & 64.8 & 0.07 & $3.56 \pm 0.72$ \\
\hline
\end{tabular}

${ }^{\mathrm{a} D P}$ of polymers were calculated from ${ }^{1} \mathrm{H}$ NMR.

${ }^{\mathrm{b}}$ Conversion $=$ repeating unit of $\mathrm{PtBA} /\left([\mathrm{tBA}] /\left[\mathrm{PEG}_{113}-b-\mathrm{PS}_{100}\right]\right) \times 100 \%$

${ }^{*}$ Not measured. 


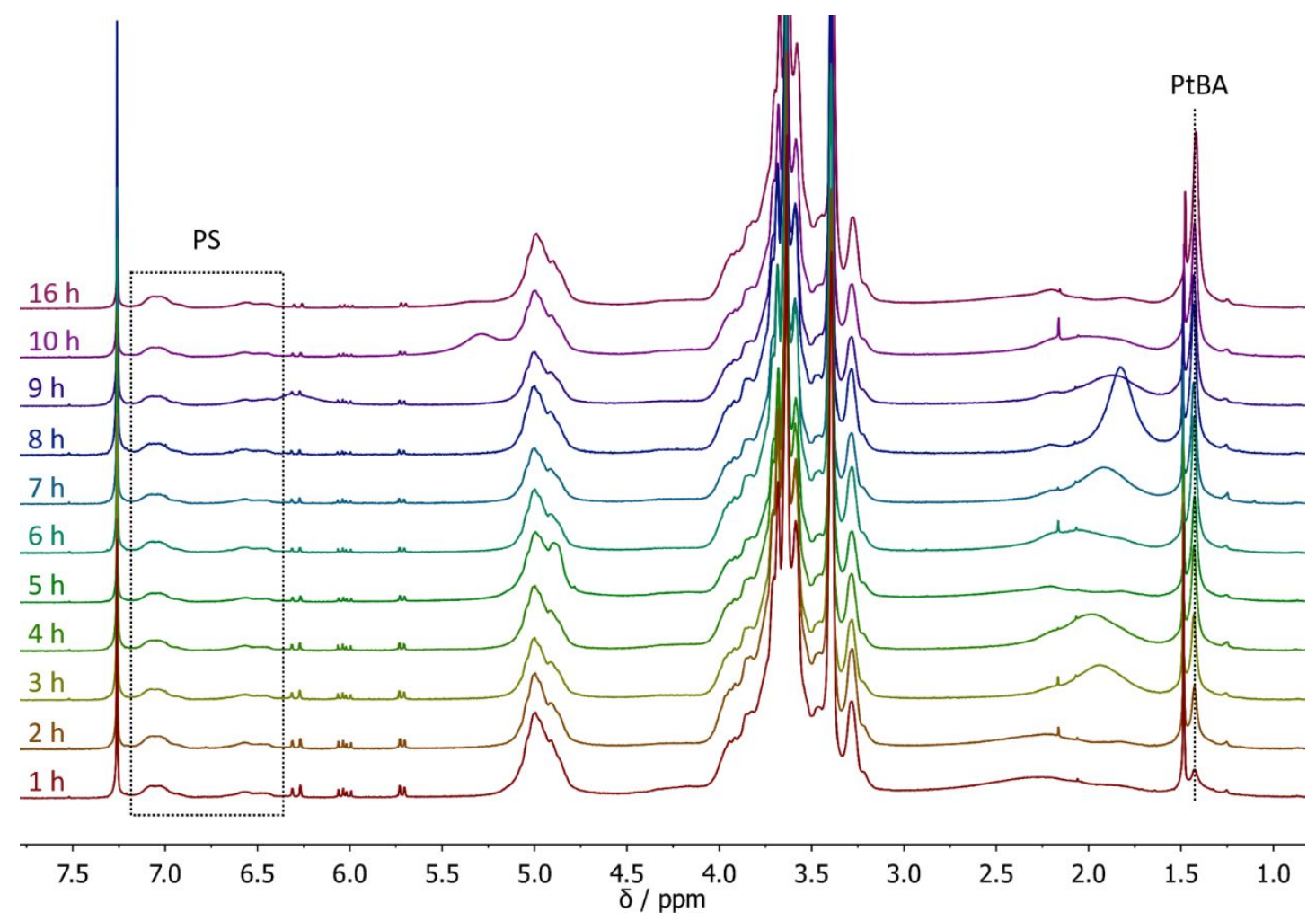

Figure S18. ${ }^{1} \mathrm{H}$ NMR spectra $\left(400 \mathrm{MHz}, \mathrm{CDCl}_{3}\right)$ of suspensions collected at specific time points during dispersion polymerization of $\mathrm{M} \beta \mathrm{CD} / \mathrm{tBA}$ (targeting $\mathrm{PEG}_{113}-b-\mathrm{PS}_{100}-b-\mathrm{PtBA}_{200}$ ). DP of $\mathrm{PtBA}=[1 / 9 \times$ integration of PtBA(1.42 ppm)]/ [1/500 $\times$ integration of PS(7.2-6.4 ppm)].
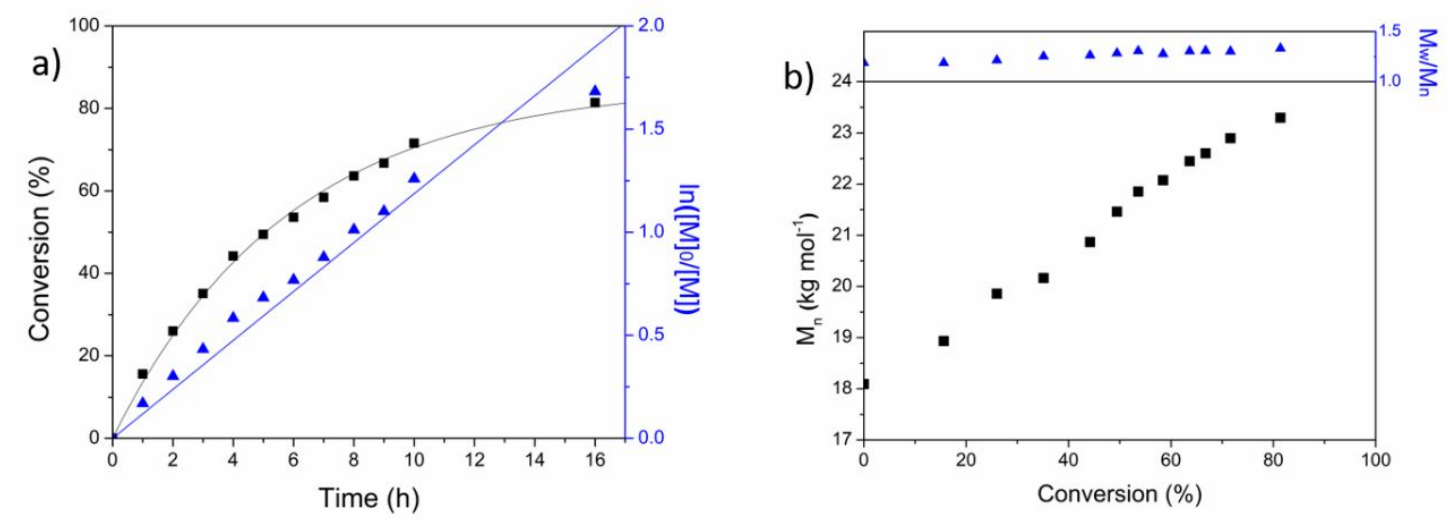

Figure S19. (a) $\ln \left([\mathrm{M}]_{0} /[\mathrm{M}]\right)$ and conversion $v s$. time and (b) molecular weight and $D v s$. conversion plots for the polymerization of $\mathrm{M} \beta \mathrm{CD} / \mathrm{tBA}$ in water at $70{ }^{\circ} \mathrm{C}$. Solid content $=3 \mathrm{wt} \%$. $[\mathrm{ACVA}] /\left[\mathrm{PEG}_{113^{-}}\right.$ $\left.b-\mathrm{PS}_{100}\right] /[\mathrm{tBA}] /[\mathrm{M} \beta \mathrm{CD}]=0.3 / 1 / 200 / 200$. 


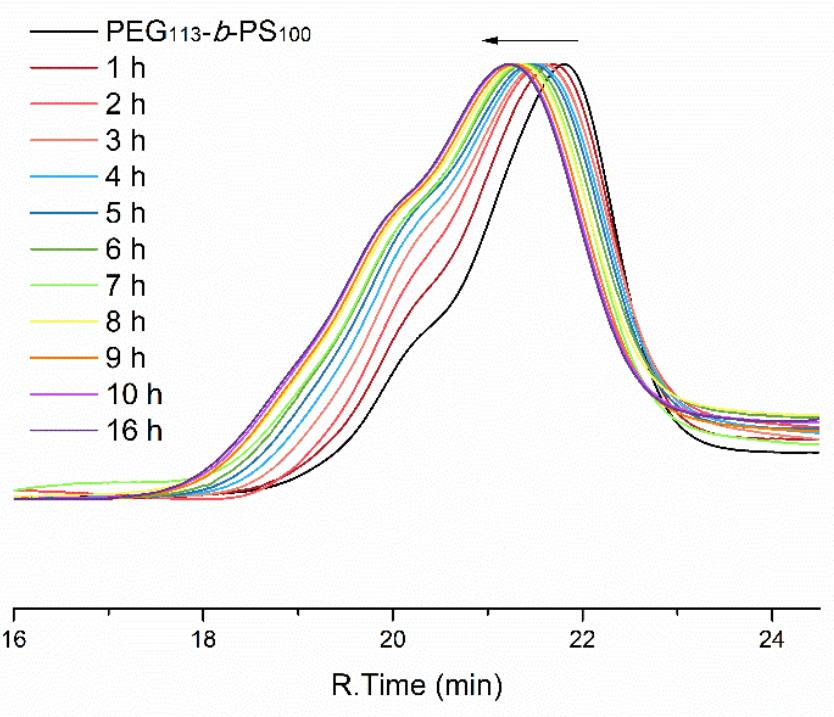

Figure S20. GPC traces of $\mathrm{PEG}_{113}-b-\mathrm{PS}_{100}$ and $\mathrm{PEG}_{113}-b-\mathrm{PS}_{100}-b-\mathrm{PtBA}_{\mathrm{x}}$ collected at specific time points during dispersion polymerization of $\mathrm{M} \beta \mathrm{CD} / \mathrm{tBA}$ (targeting $\left.\mathrm{PEG}_{113}-b-\mathrm{PS}_{100}-b-\mathrm{PtBA}_{200}\right)(\mathrm{DMF}$ as eluent, PMMA standards).

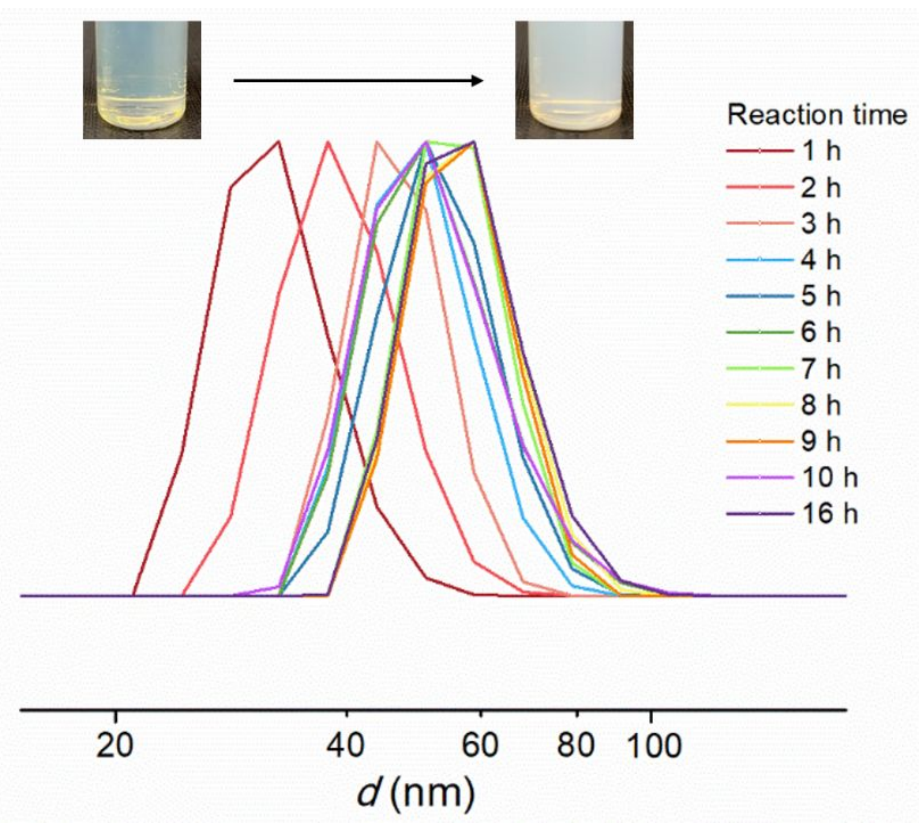

Figure S21. DLS curves of suspensions collected at specific time points during dispersion polymerization of $\mathrm{M} \beta \mathrm{CD} / \mathrm{tBA}$ (targeting $\mathrm{PEG}_{113}-b-\mathrm{PS}_{100}-b-\mathrm{PtBA}_{200}$ ). Inset photos show the comparison of cloudiness before and after polymerization. 

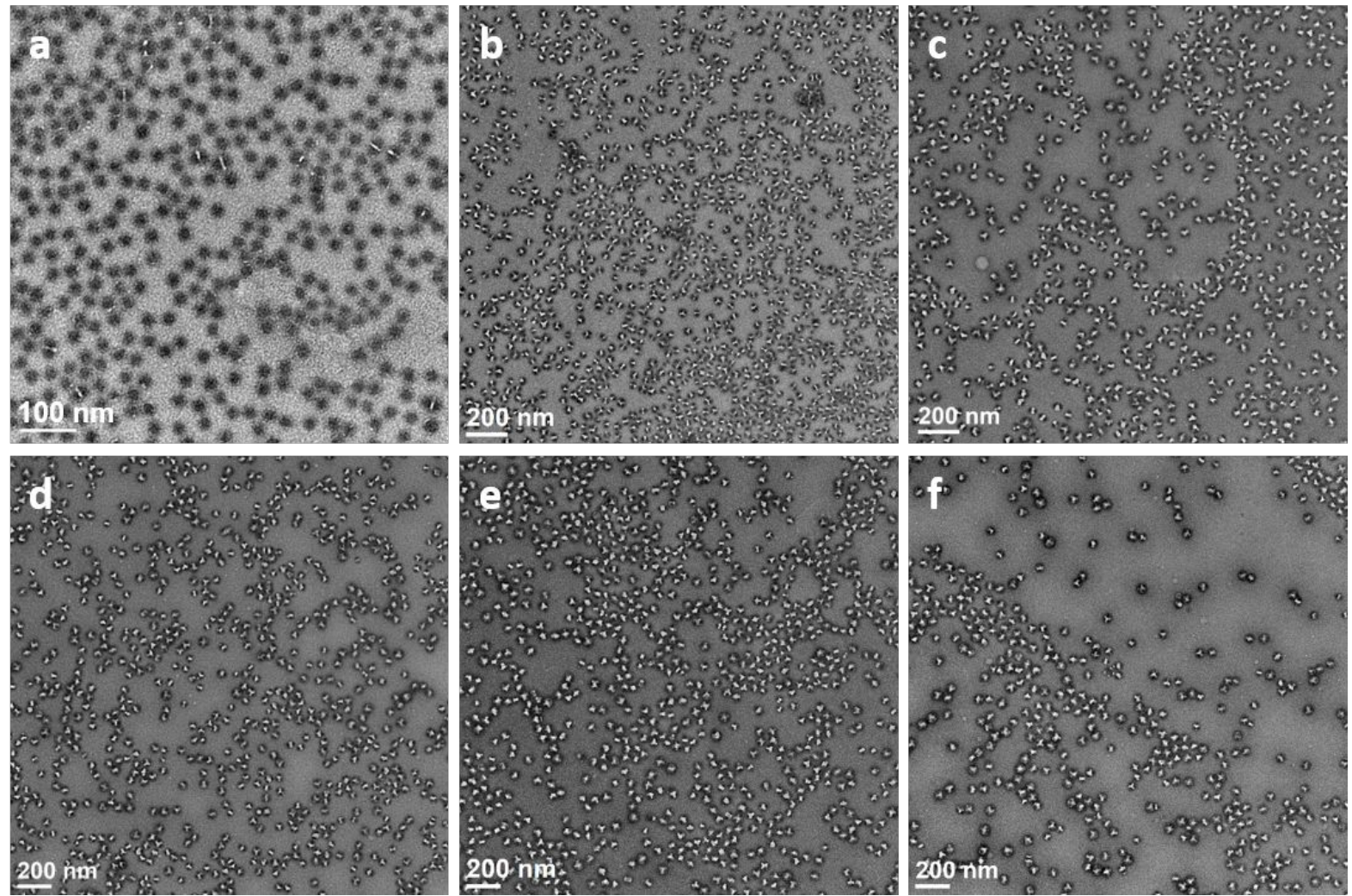

Figure S22. Representative TEM images of $E_{113} S_{100} T_{x} A X_{n}$-type CMs collected at specific time points during dispersion polymerization of $\mathrm{M} \beta \mathrm{CD} / \mathrm{tBA}$ (targeting $\mathrm{PEG}_{113}-b-\mathrm{PS}_{100}-b-\mathrm{PtBA}_{200}$ ). (a) $\mathrm{x}=31$, $V_{\mathrm{C}} / V_{\mathrm{B}}=0.40$, (b) $\mathrm{x}=70, V_{\mathrm{C}} / V_{\mathrm{B}}=0.91$, (c) $\mathrm{x}=99, V_{\mathrm{C}} / V_{\mathrm{B}}=0.1 .28$, (d) $\mathrm{x}=117, V_{\mathrm{C}} / V_{\mathrm{B}}=1.51$, (e) $\mathrm{x}=134$, $V_{\mathrm{C}} / V_{\mathrm{B}}=1.73$, (f) $\mathrm{x}=163, V_{\mathrm{C}} / V_{\mathrm{B}}=2.10$.
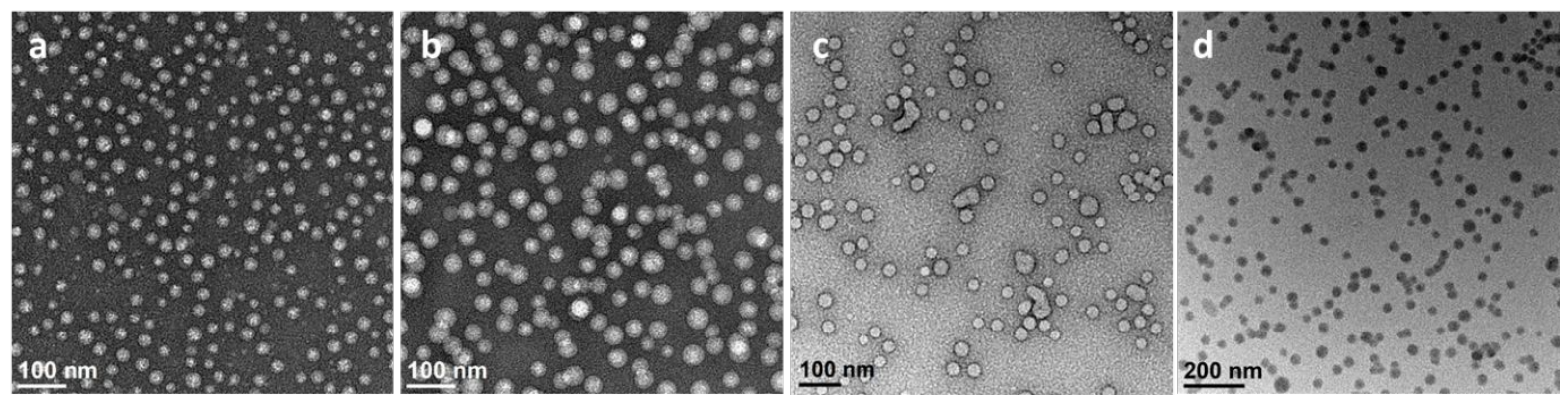

Figure S23. TEM images of (a) $\mathrm{E}_{113} \mathrm{~T}_{85}$, (b) $\mathrm{E}_{113} \mathrm{~T}_{180}$ and (c) $\mathrm{E}_{113} \mathrm{~T}_{85} \mathrm{~S}_{100}$ (UA stained) (d) $\mathrm{E}_{113} \mathrm{~T}_{85} \mathrm{~S}_{100}$ (unstained). 


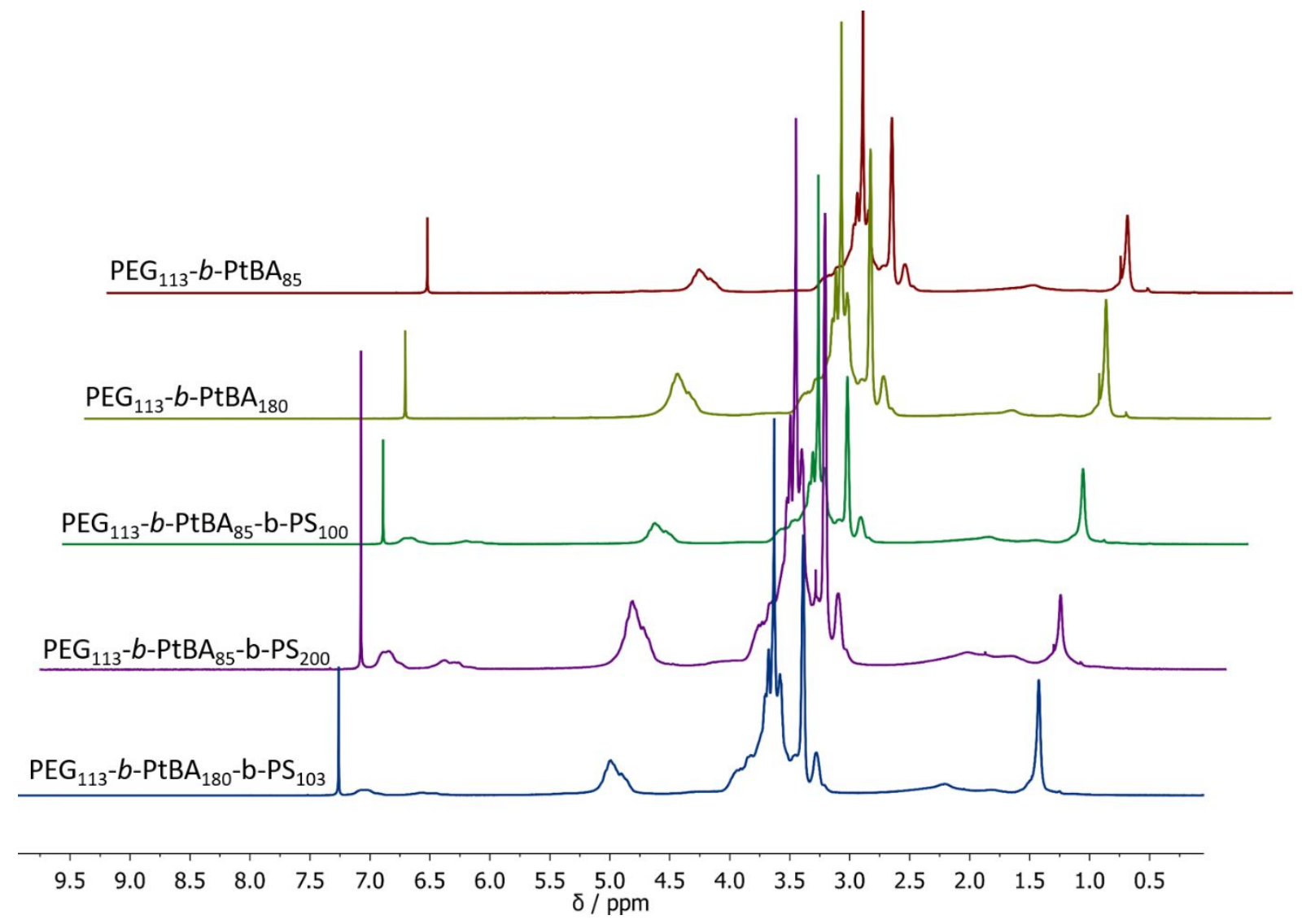

Figure S24. ${ }^{1} \mathrm{H}$ NMR spectra ( $400 \mathrm{MHz}, \mathrm{CDCl}_{3}$ ) of $\mathrm{E}_{113} \mathrm{~T}_{85}, \mathrm{E}_{113} \mathrm{~T}_{180}$ and $\mathrm{E}_{113} \mathrm{~T}_{\mathrm{m}} \mathrm{S}_{\mathrm{x}}$.

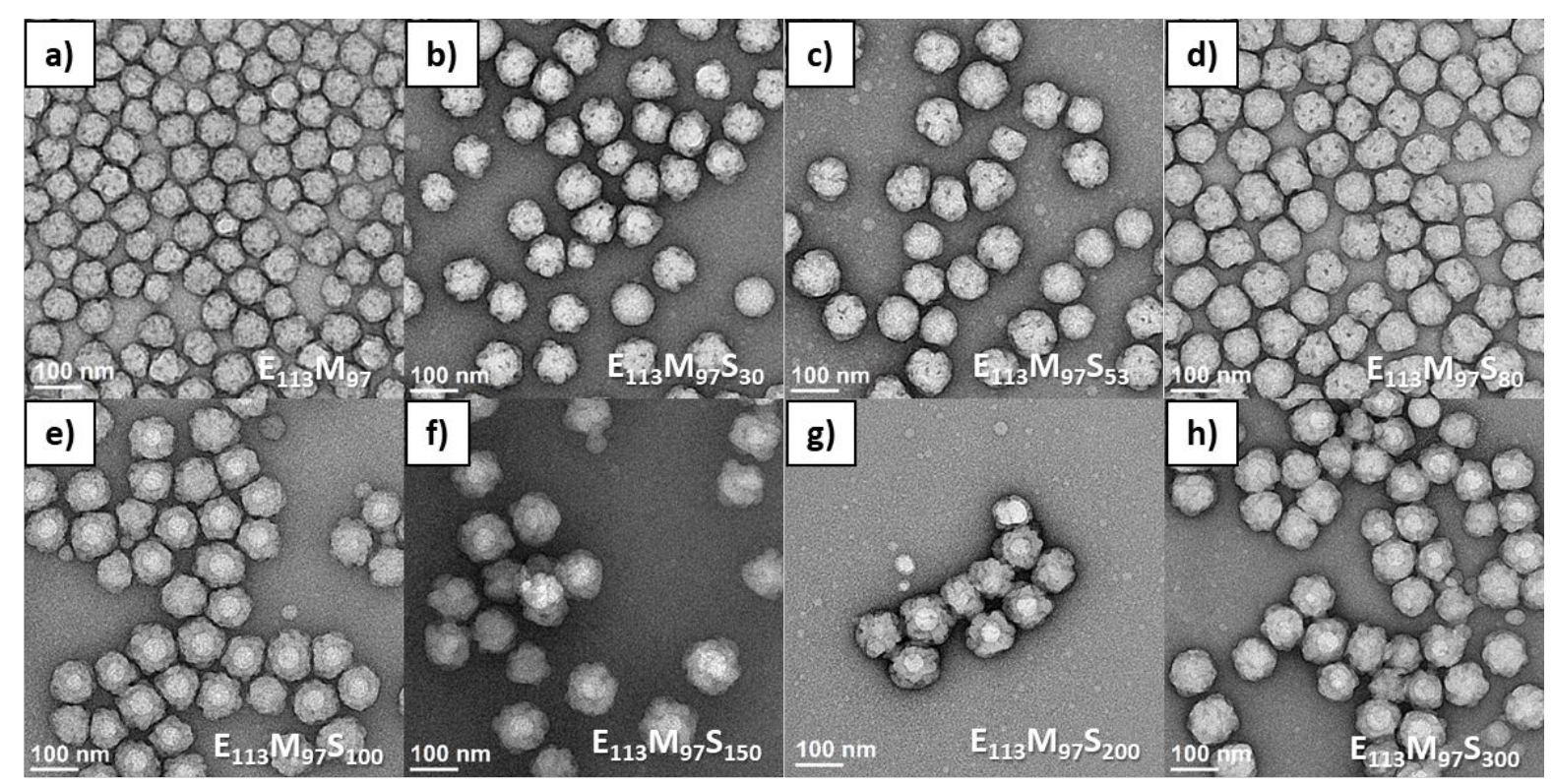

Figure S25. TEM images of synthesized $E_{113} M_{97} S_{x}(x=0-300)$ terpolymer nanoparticles (UA stained). 


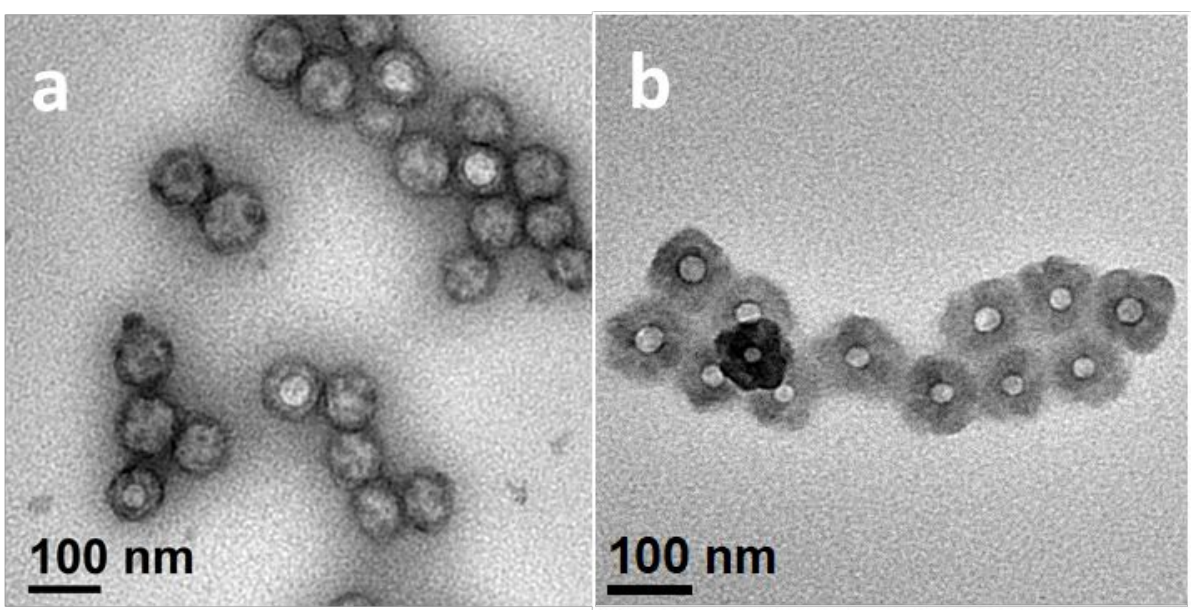

Figure S26. TEM images of synthesized (a) $\mathrm{E}_{113} \mathrm{M}_{97} \mathrm{~S}_{100}\left(\mathrm{UA}-\mathrm{RuO}_{4}\right.$ stained) and (b) $\mathrm{E}_{113} \mathrm{M}_{97} \mathrm{~S}_{100}$ (unstained) raspberry-like particles.

\section{References}

1. Wan, J.; Fan, B.; Liu, Y.; Hsia, T.; Qin, K.; Junkers, T.; Teo, B. M.; Thang, S. H., Room Temperature Synthesis of Block Copolymer Nano-Objects with Different Morphologies via Ultrasound Initiated RAFT Polymerization-Induced Self-Assembly (sono-RAFT-PISA). Polym. Chem. 2020, 11 (21), 3564-3572.

2. Girifalco, L.; Good, R. J., A Theory for the Estimation of Surface and Interfacial Energies. I. Derivation and Application to Interfacial Tension. J. Phys. Chem. 1957, 61 (7), 904-909.

3. Madison, P. H.; Long, T. E., Carbohydrate/Monomer Complexes in Aqueous Polymerizations: Methylated- $\beta$-cyclodextrin Mediated Aqueous Polymerization of Hydrophobic Methacrylic Monomers. Biomacromolecules 2000, 1 (4), 615-621.

4. Luo, Y.; Tsavalas, J.; Schork, F. J., Theoretical Aspects of Particle Swelling in Living Free Radical Miniemulsion Polymerization. Macromolecules 2001, 34 (16), 5501-5507.

5. Taura, D.; Taniguchi, Y.; Hashidzume, A.; Harada, A., Macromolecular Recognition of Cyclodextrin: Inversion of Selectivity of $\beta$-Cyclodextrin toward Adamantyl Groups Induced by Macromolecular Chains. Macromol. Rapid Commun. 2009, 30 (20), 1741-1744.

6. $\quad$ Chen, X.; Liu, L.; Huo, M.; Zeng, M.; Peng, L.; Feng, A.; Wang, X.; Yuan, J., Direct Synthesis of Polymer Nanotubes by Aqueous Dispersion Polymerization of a Cyclodextrin/Styrene Complex. Angew. Chem. Int. Ed. 2017, 56 (52), 16541-16545. 